\title{
Postoperative lleus and Postoperative Gastrointestinal Tract Dysfunction: Pathogenic Mechanisms and Novel Treatment Strategies Beyond Colorectal Enhanced Recovery After Surgery Protocols
}

\section{OPEN ACCESS}

Edited by: Luca Antonioli, University of Pisa, Italy

Reviewed by: Nathalie Stakenborg, KU Leuven, Belgium

Oksana Zayachkivska,

Danylo Halytsky Lviv National Medical

University, Ukraine

*Correspondence:

Fievos L. Christofi

fedias.christofi@osumc.edu

Specialty section: This article was submitted to Gastrointestinal and Hepatic Pharmacology, a section of the journal

Frontiers in Pharmacology

Received: 16 July 2020 Accepted: 29 September 2020 Published: 24 November 2020

Citation:

Mazzotta E, Villalobos-Hernandez EC, Fiorda-Diaz J, Harzman A and Christofi

FL (2020) Postoperative lleus and Postoperative Gastrointestinal Tract Dysfunction: Pathogenic Mechanisms and Novel Treatment Strategies

Beyond Colorectal Enhanced Recovery After Surgery Protocols.

Front. Pharmacol. 11:583422. doi: 10.3389/fphar.2020.583422

\author{
Elvio Mazzotta ${ }^{1}$, Egina Criseida Villalobos-Hernandez ${ }^{1}$, Juan Fiorda-Diaz ${ }^{1}$, Alan Harzman ${ }^{2}$ \\ and Fievos L. Christofi ${ }^{1 *}$ \\ ${ }^{1}$ Department of Anesthesiology, The Ohio State University Wexner Medical Center, Columbus, OH, United States, ${ }^{2}$ Department \\ of Surgery, The Ohio State University Wexner Medical Center, Columbus, OH, United States
}

Postoperative ileus (POI) and postoperative gastrointestinal tract dysfunction (POGD) are well-known complications affecting patients undergoing intestinal surgery. Gl symptoms include nausea, vomiting, pain, abdominal distention, bloating, and constipation. These iatrogenic disorders are associated with extended hospitalizations, increased morbidity, and health care costs into the billions and current therapeutic strategies are limited. This is a narrative review focused on recent concepts in the pathogenesis of POI and POGD, pipeline drugs or approaches to treatment. Mechanisms, cellular targets and pathways implicated in the pathogenesis include gut surgical manipulation and surgical trauma, neuroinflammation, reactive enteric glia, macrophages, mast cells, monocytes, neutrophils and ICC's. The precise interactions between immune, inflammatory, neural and glial cells are not well understood. Reactive enteric glial cells are an emerging therapeutic target that is under intense investigation for enteric neuropathies, GI dysmotility and POI. Our review emphasizes current therapeutic strategies, starting with the implementation of colorectal enhanced recovery after surgery protocols to protect against $\mathrm{POI}$ and POGD. However, despite colorectal enhanced recovery after surgery, it remains a significant medical problem and burden on the healthcare system. Over 100 pipeline drugs or treatments are listed in Clin.Trials.gov. These include $5 \mathrm{HT}_{4} \mathrm{R}$ agonists (Prucalopride and TAK 954), vagus nerve stimulation of the ENS-macrophage nAChR cholinergic pathway, acupuncture, herbal medications, peripheral acting opioid antagonists (Alvimopen, Methlnaltexone, Naldemedine), anti-bloating/ flatulence drugs (Simethiocone), a ghreline prokinetic agonist (Ulimovelin), drinking coffee, and nicotine chewing gum. A better understanding of the pathogenic

Abbreviations: ATP, adenosine- 5 '-triphosphate; CERAS, colorectal enhanced recovery after surgery; ET-1, endothelin-1; ETBR, endothelin-B receptor; GI, gastrointestinal; NG, nasogastric; POGD, postoperative gastrointestinal tract dysfunction; POI, postoperative ileus; 5-HT, 5-hydroxytryptamine (serotonin); IL-1 $\beta$, interleukin-1 $\beta$; IL-6, interleukin-6; IL-8, interleukin-8; IL-1R, interleukin-1 receptor; VNS, vagus nerve stimulation 
mechanisms for short and long-term outcomes is necessary before we can develop better prophylactic and treatment strategies.

Keywords: postoperative gastrointestinal tract dysfunction, postoperative ileus, colorectal enhanced recovery after surgery, gastrointestinal surgery, enteric glia, prokinetic agents, mechanosensation, $5 \mathrm{HT} 4$ receptor

\section{INTRODUCTION}

Postoperative gastrointestinal dysfunction (POGD), commonly referred to as postoperative ileus (POI), is a widely known complication characterized by a transient impairment of gastrointestinal (GI) function after abdominal surgery. This clinical entity has been linked to a significant perioperative morbidity (e.g., enteral nutrition delay and patient discomfort) with subsequent financial burden due to extended hospitalization (Behm and Stollman, 2003; Wolthuis et al., 2016; Hedrick et al., 2018). In the United States, POI may increase hospital expenses up to $15 \%$ with an approximate annual cost of $\$ 1.46$ billion (Goldstein et al., 2007).

Nausea, vomiting, abdominal tenderness and distention, absence of normal bowel sounds and/or delay in the passage of flatus and stool are some of the signs and symptoms associated with POI (Vather et al., 2013). However, the identification of other symptoms and risk factors may be significantly limited due to the ambiguous and heterogeneous definition of POI, making it even more difficult to estimate its overall incidence (Vather et al., 2013; Wolthuis et al., 2016). In 2018, the American Society for Enhanced Recovery After Surgery (ERAS) and Perioperative Joint Consensus considered forgoing the traditional definition of POI for a more functional definition and scoring system of POGD, to precisely describe the clinical manifestations of the GI Disorder (Hedrick et al., 2018). Therefore, a scoring system was proposed based on Intake, Feeling nauseated, Emesis, physical Exam, and Duration of symptoms (I-FEED), which defined three categories of postoperative GI functional impairment (Hedrick et al., 2018):

- Normal (I-FEED score 0-2): patients tolerate diet without bloating symptoms but may experience postoperative nausea and vomiting (PONV) within the first 24-48 postoperative hours.

- Postoperative GI Intolerance (POGI) (I-FEED score 3-5): these patients experience nausea, small-volume emesis, and bloating with or without bowel movements (stools or flatus) $48 \mathrm{~h}$ after surgery. However, most of them tolerate oral fluids and no nasogastric tube (NGT) is required.

- Postoperative GI Dysfunction (POGD) (I-FEED score $>6$ ): is the most severe level of impaired GI function. Patients develop painful abdominal distention with tympany, no bowel movements, nausea resistant to antiemetics and large-volume bilious emesis.

Currently, the mechanisms involved in the onset, duration and severity of POI and POGD remain unclear. Nevertheless, its association with spinal-intestinal sympathetic neural reflexes, sympathetic hyperactivity, inflammatory mediators, opioids use, electrolyte abnormalities and exacerbation by anesthetic or surgical techniques (e.g., size of the surgical incision and tissue manipulation), have all been extensively described as potential pathogenic mechanisms (Lobo et al., 2002; Luckey et al., 2003; Bauer and Boeckxstaens, 2004; Shah et al., 2011).

In addition, the occurrence and duration of POGD may also be determined by intestinal inflammation as measured in peritoneal fluid or surgical tissues, being longer periods of POI reported after open surgery when compared to laparoscopic minimally invasive procedures (Gomez-Pinilla et al., 2014; Vather et al., 2015).

This is a narrative review about POI and POGD and is not intended to provide a comprehensive description and understanding of the science related to the iatrogenic disease. The published scientific literature indexed in PubMed (Medline database), Scopus, LILACS and MEDSCAPE were searched for studies. The search focused on articles from 2015 to 2020, key words indexed in those articles and similar ones, as well as selected earlier publications. This review intends to focus on recent concepts of pathogenic mechanisms of POI and POGD, covering cellular targets and how current and pipeline treatments modulate these cellular mechanisms. An emerging cellular target of considerable interest is the "reactive enteric glial cell phenotype" in the pathogenic mechanism. CERAS guidelines for the management of POI and POGD, new therapeutic strategies and approaches to treatment in the neurogastroenterology field are discussed. Current Trials on POI and POGD listed in Clinical Trials.gov are briefly summarized in our review, with emphasis on cellular mechanisms.

\section{PATHOGENIC CELLULAR MECHANISMS AND PATHWAYS LEADING TO POSTOPERATIVE ILEUS AND TREATMENT STRATEGIES}

This section will summarize pathogenic cellular mechanisms and signaling pathways leading to POI and highlight where in the inflammatory response following surgical intestinal handling treatments are intervening. Surgical trauma and gut manipulation trigger an inflammatory response in the muscularis externa involving a variety of immune, inflammatory cells (macrophages, dendritic cells, mast cells, monocytes, neutrophils), reactive enteric glia, neurons, smooth muscle cells, ICCs, enteroendocrince cells, epithelial cells, as well as the microbiome in the lumen of the gut. The resulting neuroinflammatory response leads to gastrointestinal dysfunction and postoperative ileus, associated with disturbances in motility, slower transit and constipation. Activation of the extrinsic nerve pathway via vagus nerve stimulation contributes to protective mechanisms. Figure 1 illustrates the cellular mechanisms implicated in the 


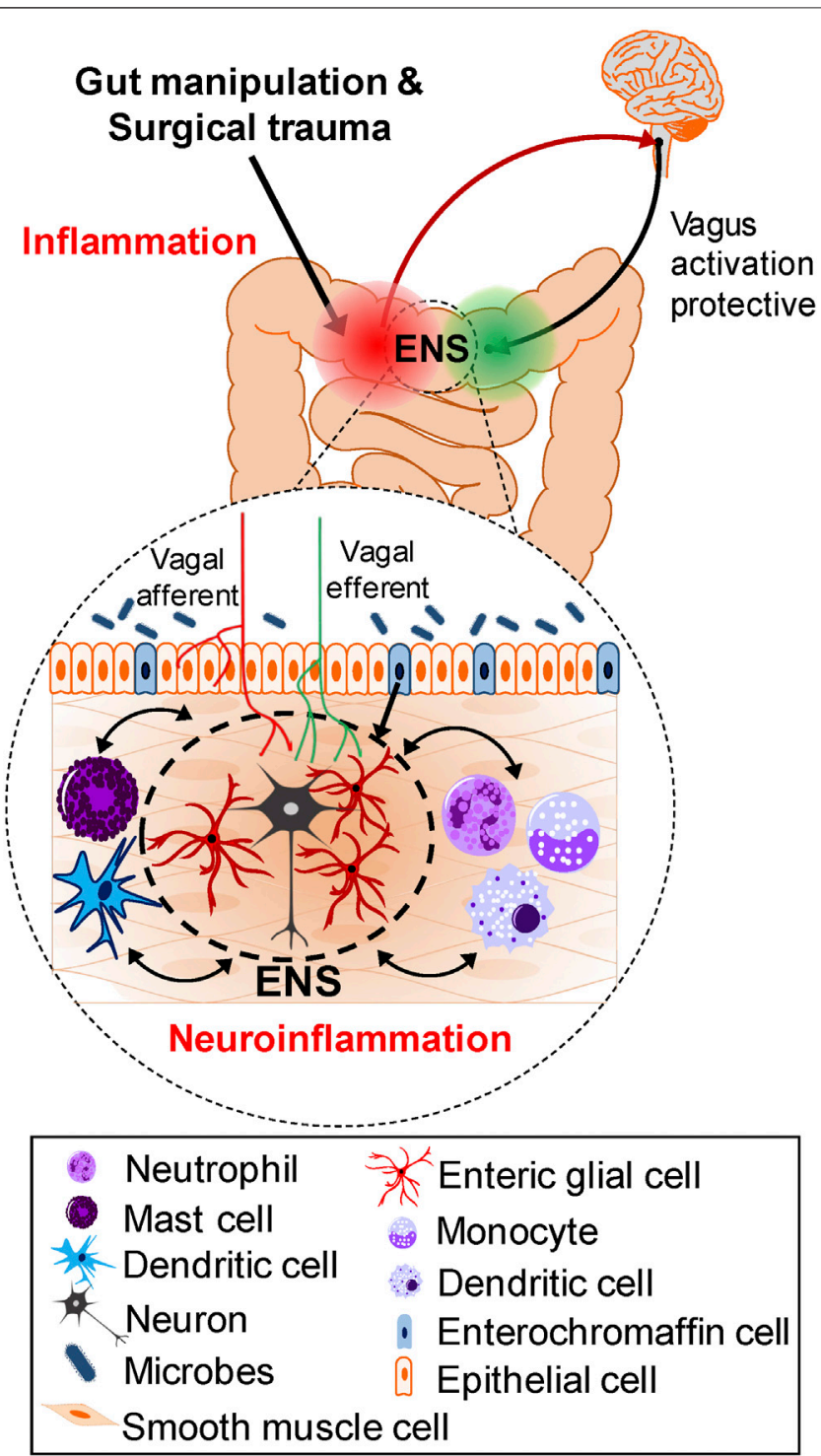

FIGURE 1 | Cellular mechanisms and Pathways involved in the Pathogenesis of POI and POGD. Gut manipulation and surgical trauma triggers an inflammatory response in the muscularis externa. A variety of immune, inflammatory cells, enteric glia, neurons, smooth muscle cells, ICCs, enteroendocrine cells and microbes in the lumen of the gut, all contribute to the inflammatory response. Interactions in both directions exist between these cells in the intestinal wall but the precise trigger mechanisms activated for the cascade of events leading to POI are not known. In the context of inflammation, immune cell activation in coordination with reactive glia, promote monocyte and neutrophil infiltration, and all together produce a neuroinflammatory response leading to smooth muscle dysfunction and postoperative ileus. In contrast to chronic intestinal inflammation such as in $\mathrm{IBD}$, after the surgery, in the absence of intestinal surgical manipulation, the ENS and intestinal motility eventually recover. The

vagus - ENS - macrophage cholinergic ( $\mathrm{nAChR}$ ) pathway is a protective antiinflammatory pathway, and vagus nerve stimulation can protect against development of POI and POGD. pathogenesis of POI and POGD—-these are potential targets for treatment interventions.

The available evidence suggests it is likely that complex communication pathways exist between neurons, glia, immune cells, as well as other cells in the thickness of the gut wall, including ICC/fibroblast-like cells/smooth muscle cells that may contribute to the pathogenesis of POI and POGD. The precise interactions between different cells is not well understood. Findings from key recent studies on the role of various cell types will be summarized in this review. Muscularis macrophages are key immune cells in intestinal homeostasis and disease (Wehner and Engel, 2017; Stakenborg et al., 2019). Interactions between tissue macrophages and the enteric nervous system (ENS) are known to contribute to intestinal motility, serve as a protective mechanism during injury and infections, but they can also contribute to tissue damage in POI and other GI disorders. Extrinsic innervation modulates muscularis macrophages. Neuronal regulation of intestinal immune functions in health and disease was reviewed elsewhere (Fornai et al., 2018).

Enteric glial cells are involved in functional crosstalk with all other cells in the gut wall, including muscularis macrophages (Grubišić et al., 2020), although the consequences of all these communications remain largely unknown (Chow and Gulbransen, 2017; Fettucciari et al., 2017; Langness et al., 2017; Gulbransen and Christofi, 2018; Valès et al., 2018).

\section{Vagus - Intestinal Cholinergic (nAChR) Anti-Inflammatory Pathway, Vagus Nerve Stimulation, 5- $\mathrm{HT}_{4} \mathrm{R}$ Agonists, Enteral Nutrition}

Goverse et al. (2016) recently reviewed the role of the intestinal cholinergic anti-inflammatory pathway involving the vagus nerve, the ENS and muscularis macrophages. Vagus nerve stimulation (VNS) has been shown to prevent POI in preclinical models by reducing activation of $\alpha 7$-nicotinic receptor ( $\mathrm{a} 7 \mathrm{nAChR})$ positive muscularis macrophages and dampening surgery-induced gut inflammation (de Jonge et al., 2005; Cailotto et al., 2012; Matteoli et al., 2014; Stakenborg et al., 2017). In a pilot clinical study, VNS was associated with a significant reduction in interleukin 6 (IL-6) and IL-8 production in patients undergoing GI surgery (Stakenborg et al., 2017). The effect of VNS is likely mediated via enteric neurons to influence macrophages, since vagus nerve endings synapse with enteric neurons that are in close proximity to muscularis macrophages.

Enteric neurons dampen muscularis macrophage activation, and this effect is mimicked by prucalopride, the $5 \mathrm{HT}_{4}$ receptor $\left(5 \mathrm{HT}_{4} \mathrm{R}\right)$ agonist (Stakenborg et al., 2019). Furthermore, similar to VNS, preoperative treatment with prucalopride protects against POI by preventing intestinal inflammation and shortening POI in both mice and humans. In humans, data was obtained from a randomized placebo-controlled pilot 
study of 42 patients. An earlier randomized clinical trial with prucalopride was also shown to reduce the duration of POI after elective gastrointestinal surgery, and it proved to be a safe and effective treatment without affecting post-operative complications (Gong et al., 2016). It could be concluded from these studies that preoperative administration of $5-\mathrm{HT}_{4}$ agonists should be further evaluated as a prophylactic treatment of POI.

Another study with the $5 \mathrm{HT}_{4} \mathrm{R}$ agonist mosapride was shown to attenuate both macrophage and neutrophil recruitment into inflamed sites in experimental POI (Kimura et al., 2019). Recruitment of macrophage and neutrophils are regulated by different types of AChR, a7nAChR on muscularis macrophages and M2AChR (possibly in the ENS).

5 -Hydroxytryptamine $(5-\mathrm{HT})$ is one of the most important enteric modulators of the peristaltic reflex (McLean et al., 1997; Linan-Rico et al., 2016). The $5-\mathrm{HT}_{4} \mathrm{R}$ agonist tegaserod was shown to be effective in treating constipation in a subset of patients diagnosed with constipation-predominant irritable bowel syndrome (C-IBS) (Prather et al., 2000; Evans et al., 2007). As a result, $5-\mathrm{HT}_{4} \mathrm{R}$ agonists have emerged as a novel therapeutic alternative for patients experiencing GI motility disorders.

Recent evidence suggests that the $5 \mathrm{HT}_{4} \mathrm{R}$ agonist prucalopride reduces local tissue inflammation (Bouras et al., 1999; Gong et al., 2016; Stakenborg et al., 2019). Moreover, early studies in animals and healthy humans have shown that a new selective $5-\mathrm{HT}_{4} \mathrm{R}$ agonist, TAK-954 (previously known as TD-8954) has a potent prokinetic effect. In a phase II clinical trial (NCT03281577), TAK954 significantly improved gastric emptying when compared to metoclopramide (Beattie et al., 2011; Chapman et al., 2018). Currently, a phase II multi-center Clinical Trial with TAK-954 is underway on POI and POGD.

Abdominal surgery induces gastric ileus and activation of M1like macrophages in gastric myenteric plexus is likely involved in the pathogenic mechanism since central vagal activation dampens postoperative gastric ileus and reduces intestinal inflammation (Yuan and Taché, 2017).

\section{TRPM2 in Macrophages}

TRPM2 is a cation channel that is highly expressed in macrophages and other immune/inflammatory cells and regulates detrimental immune cell invasion in disease states (Haraguchi et al., 2012; Isami et al., 2013; Knowles et al., 2013; Gelderblom et al., 2014). Matsumoto et al. (2018) showed that activation of TRPM2 in resident muscularis macrophages induces release of chemokines and cytokines and in turn promotes infiltration of monocytes and neutrophils into the muscle to cause dysmotility. TRPM2 deficiency blocks or ameliorates these effects. Therefore, more studies are needed to explore the role of TRPM2 as a potential target in treating dysmotility due to POI.

\section{CXCL1 Release from Macrophages}

The cytokine CXCL1 released from macrophages during intestinal surgical trauma was shown to suppress intestinal contractility. CXCL1 may provide another target for intervention to ameliorate POI and deserves further investigation (Docsa et al., 2020).

\section{CCR2-Dependent Monocyte-Derived Macrophages}

In contrast to resident macrophages, CCR2-dependent monocyte-derived macrophages play a critical role in restoring intestinal homeostasis (Serhan and Savill, 2005; Shechter et al., 2009; Stoffels et al., 2009; Nahrendorf et al., 2010; Grainger et al., 2013; Zigmond et al., 2014) and this is also the case after surgical trauma in POI (Farro et al., 2017). GI transit recovery was delayed after gut manipulation in mice with defective CCR2-dependent monocyte migration to tissues (i.e., in $\mathrm{Ccr} 2^{-1-}$ mice). Consistent with this, bone marrow reconstitution and treatment with macrophage colony stimulating factor 1 enhanced monocyte recruitment and differentiation of macrophages, and could restore GI transit in $\mathrm{Ccr} 2^{-/-}$mice by releasing anti-inflammatory cytokines. This raises the possibility that enhancing macrophage physiological repair functions is a potential treatment strategy for POI.

Monocyte-derived macrophages are the major source of IL-10 in POI. Leukocyte-derived interleukin-10 aggravates POI and in IL-10 deficiency, neutrophil extravasation into the postsurgical bowel wall is reduced and protects mice from developing POI (Stein et al., 2018).

\section{Mast Cells}

Lipid rich enteral nutrition is a physiologic approach to activate the cholinergic vagal anti-inflammatory pathway by stimulating cholecystokinin receptors (Luyer et al., 2005). Early oral nutrition improves POI through the TRPA1/CCK1-R mediated mast cellnerve axis. Activation of the TRPA1 pathway regulates CCK1-R to stabilize mast cells, but TRPA1 is not the target of the downstream CCK1-R pathway (Sun et al., 2020). In a randomized control trial, early enteral nutrition in patients undergoing major rectal surgery has been shown to reduce POI by improving recovery of gut motility, a reduction in the time to first defecation and length of hospital stay (Boelens et al., 2014). The contribution of mast cells to POI has been reviewed in experimental and clinical studies. Intestinal manipulation during surgery and mast cell degranulation releases pro-inflammatory mediators that can trigger formation of a localized infiltrate in the gut wall. The inflammation plays a significant role in POI by disrupting GI motility that also includes non-manipulated bowel segments (Peters et al., 2015). An earlier study provided proof of the concept that intestinal handling-induced mast cell activation and inflammation in human POI. Mast cell activation (tryptase release) and inflammation were determined in peritoneal lavage fluid in patients undergoing conventional and minimal invasive surgery. The study showed that intestinal handling triggers mast cell activation and inflammation associated with prolonged POI, that may in part explain faster recovery with minimal invasive surgery, although other cells and mechanisms are likely to be involved as well (The et al., 2008). The role of mast cells in functional GI disorders was reviewed by Wouters et al. (2016) and treatment with mast cell stabilizers offers a potential treatment strategy for IBS patients not responding to other therapies. Similar approaches deserve consideration in POI. 


\section{Interstitial Cells of Cajal}

Disruption of the pacemaker activity of interstitial cells of Cajal (ICC) via a nitric oxide (NO) pathway contributes to POI (Kaji et al., 2018). Administration of aminoguanidine, an inducible NO synthase inhibitor, suppressed the disruption of the ICC networks in POI. Acupuncture protects ICC's in part by regulating miR222 in a rat model of POI (Deng et al., 2019), although the underlying mechanisms remain unclear.

The effects of acupuncture on POI were also assessed in patients after colorectal resection and in colocolic anastomosis mice. Acupuncture was shown to inhibit macrophage activation, IL-6 release and miR-19a up regulation (an inflammation-related miRNA), while promoting anol restoration and KIT in ICCs. Acupuncture also reduced high serum miR-19a level in patients with colorectal surgery. In this study, acupuncture ameliorates POI via the IL-6-miR-19a-KIT Axis to protect ICC's (Deng et al., 2017).

\section{Role of Endogenous Gases Nitric Oxide, Carbon Monoxide, and Hydrogen Sulfide in Postoperative lleus}

The endogenous gases NO, carbón monoxide (CO), and hydrogen sulfide $\left(\mathrm{H}_{2} \mathrm{~S}\right)$ play a role in POI. The possible involvement of $\mathrm{NO}$ in the pathogenesis of POI was described many years ago (Moojen et al., 1999). Carbon monoxide treatment was shown to ameliorate POI in mice (Moore et al., 2003; Nakao et al., 2006). More recent studies have shown that $\mathrm{H}_{2} \mathrm{~S}$ is involved in cellular signaling and cytoprotection of the colonic mucosa and other organ systems (Calvert et al., 2010; Matsunami et al., 2012; Kimura, 2013). For example, $\mathrm{H}_{2} \mathrm{~S}$ releasing nonsteroidal anti-inflammatory drugs (NSAIDs) protect the mucosa from ulceration (Wallace, 2007; EkundiValentim et al., 2013; Magierowski et al., 2017). Release of $\mathrm{H}_{2} \mathrm{~S}$ contributes to the anti-inflammatory effects of $\mathrm{H}_{2} \mathrm{~S}$-NSAIDs, by reducing leukocyte infiltration, COX-2 activity and IL- $1 \beta$ expression. A recent study in mice showed that the $\mathrm{H}_{2} \mathrm{~S}$-releasing naproxen derivative ATB-346 and the slow releasing $\mathrm{H}_{2} \mathrm{~S}$ donor GYY4137 were effective in reducing intestinal inflammation and restoring transit in postoperative ileus (Van Dingenen et al., 2019), suggesting that targeting the $\mathrm{H}_{2} \mathrm{~S}$ pathway in the gut is a potential target for developing a prophylactic treatment for POI. A systematic review and metaanalysis revealed that NSAIDs reduce the time to recovery of gut function after elective colorectal surgery (Milne et al., 2018). Clinical trials with $\mathrm{H}_{2} \mathrm{~S}$-releasing NSAIDs seem feasible and safe since ATB-346 has already been tested in phase 1 and phase 2 studies in patients with osteoarthritis (Wallace et al., 2018). The underlying mechanisms by which $\mathrm{H}_{2} \mathrm{~S}$ releasing compounds exert their beneficial effects in POI remain unknown.

\section{Acupuncture, Electroacupuncture and Nucleus of the Solitary Tract Neurons}

In China, acupuncture has been traditionally used as an alternative treatment of GI disorders (Takahashi, 2006). Even though several studies have determined the effectiveness of acupuncture in the prophylaxis against POI after colorectal surgery, current clinical evidence remains inconclusive (Meng et al., 2010; Deng et al., 2013; Ng et al., 2013; Zhang et al., 2014). Additional randomized controlled studies are necessary to prove or disprove its effectiveness.

Electroacupuncture (EA) is a modern way of delivering acupuncture used widely in various GI diseases around the world. EA administered at ST36 shortened the recovery time of GI and colonic transit and increased gastric emptying. The beneficial effect of EA on POI was thought to be mediated by exciting neurons in the nucleus of the solitary tract (NTS) and activating the vagus efferent nerve pathway to improve GI tract transit, but not by activating the cholinergic anti-inflammatory pathway (Fang et al., 2017).

\section{Enterochromaffin Cells}

Transient receptor potential ankyrin 1 (TRPA1) agonists improve intestinal transit in a mouse model of POI (Tsuchiya et al., 2016). TRPA1 receptors on enterochromaffin cells are a potential cellular target for the action of TRPA1 agonists. Intraluminal TRPA1 stimulation is suggested to be a potential therapeutic strategy for POI and GI motility disorders.

\section{Mesothelial Cells}

Inflammation in intestinal mesothelial cells in the abdominal cavity is an important pathogenic mechanism in clinical conditions such as POI and peritonitis. The anti-inflammatory pathway regulated via $\alpha 7 \mathrm{nAChR}$ in rat intestinal mesothelial cells may also involve enteric nerves (Mihara et al., 2017).

\section{Microbiome}

Small bowel mucosal antimicrobial defense is disturbed in a gut manipulation mouse model of POI and it is accompanied by bacterial overgrowth and translocation. IL1R activation is involved in gene expression of mucosal antimicrobial peptides that serves to protect the epithelium from an increasing microbial challenge (Stein et al., 2018).

\section{HuR/p38/MK2 Signaling Pathway}

In experimental studies in a mouse model of intraperitoneal transduction of HuR-RNAi lentivirus, suppression of $\mathrm{HuR}$ gene expression in mouse POI was shown to cause a significant reduction in inflammation (in infiltration of inflammatory cells, expression of pro-inflammatory genes, and reduction in serum cytokines) via the p38/MK2 signaling pathway (Xiong et al., 2017). The study did not evaluate the impact of Lentivirus-mediated HuR RNA interference on restoring normal GI transit in the POI model. Data suggest that $\mathrm{HuR}$ is a potential candidate drug target for the mitigation of POI, and further studies are necessary to prove this.

\section{FUTURE PERSPECTIVES: TARGETING ENTERIC GLIA}

Despite the implementation of CERAS protocols, POI and POGD remain a significant medical problem and burden on the healthcare system. A better understanding of the pathogenic 


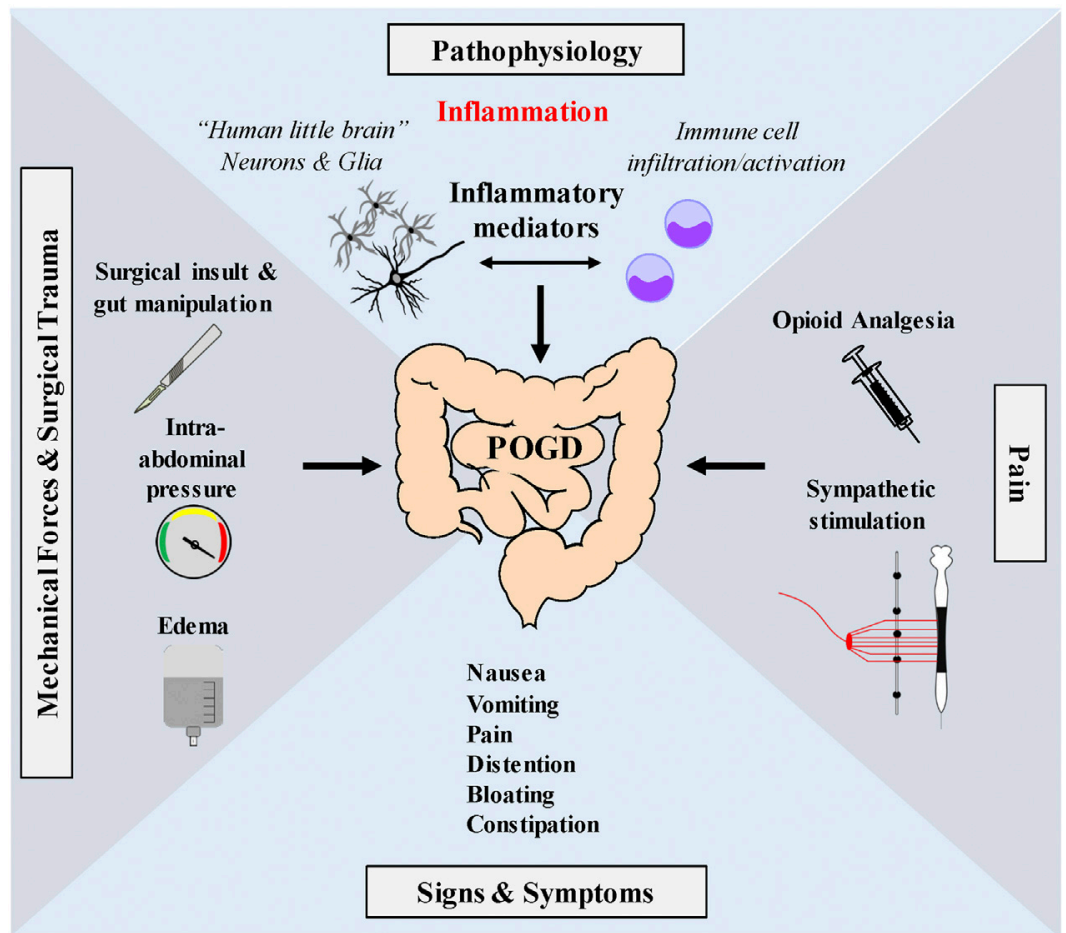

FIGURE 2 | Working hypothesis of proposed glial pathogenic mechanism of postoperative ileus-Enteric glia are very sensitive to mechanical stimulation and mechanical forces generated during peristalsis. Touch, stretch, shear stress, pressure, compression, membrane perturbations and centrifugal forces all operate during peristalsis. Mechanosensation is a normal function of enteric glia in the modulation of motility through interactions with the ENS. Abnormal mechanical forces encountered during Gl surgery such as gut manipulation, surgical insult, fluid edema or high pressure pneumoperitoneum encountered in minimal invasive laparoscopic surgery, may activate enteric glia (and immune cells) in the muscularis externa contributing to the induction of a reactive enteric glial cell phenotype. Reactive glia in coordination with immune cells release pro-inflammatory mediators that disrupt the ENS to cause Gl dysmotility associated with POI and POGD. Signs and symptoms include nausea, vomiting, Pain distention, bloating and constipation. Pain pathways also activate the sympathetic nervous system which has inhibitory effects on GI motility. Additionally, opioids, commonly used during the perioperative period to treat pain, activate peripheral $\mu$ opioid receptors in the ENS and further depress peristalsis.

mechanisms of POI and POGD in both experimental models and in the clinical setting are desperately needed. A cellular target of growing interest in the field of neurogastroenterology and motility is the enteric glial cell and in particular in GI disorders. The following section is focused on the role of glia as a therapeutic target in POI and POGD.

Enteric neuropathies are a hallmark of GI Diseases and Disorders. A growing body of evidence supports the concept that enteric glia are involved in the pathogenesis (Ochoa-Cortes et al., 2016; Gulbransen and Christofi, 2018) and "reactive glia" contribute to neuroinflammation and abnormal motility. There is great interest in enteric glia in the field of neurogastroenterology and motility-they are implicated in GI diseases and disorders including IBS, IBD, postoperative ileus, chronic morphineinduced constipation, and idiopathic constipation (OchoaCortes et al., 2016; Gulbransen and Christofi, 2018). Glial Ca ${ }^{2+}$ waves are required for normal motility, and disruption of these waves disrupts motility. Enteric glia and neurons contribute to enteric neuropathies underlying these disorders (Ochoa-Cortes et al., 2016; Chow and Gulbransen, 2017; Gulbransen and Christofi, 2018).

\section{Pathogenesis of Postoperative lleus and Postoperative Gastrointestinal Tract Dysfunction-Reactive Glial Phenotype}

A working hypothesis of the pathogenic mechanism of POI and POGD is illustrated in Figure 2. Enteric glial cells modulate neural circuit activity in the enteric nervous system (ENS) or gut "little brain" and are required for normal motility. Disruption of glial cell activity leads to abnormal motility. Enteric glia is activated by mechanical forces encountered during peristalsis that are generated by coordinated movements of the gut. Glial activation is involved in ongoing fine-tune modulation of motility through the ENS. Abnormal mechanical forces on the gut and its mesentery are encountered during intestinal surgery, which are believed to cause a "reactive glial" phenotype. Reactive glia contributes to neuroinflammation and abnormal motility associated with POI.

Gut surgical manipulation and trauma, holding the bowel in place with a self-retaining retractor throughout the case, exerting pressure on the segment or squeezing and stretching the gut can activate glia and convert them to a pathogenic state referred to as "a reactive glial phenotype" leading to POI and POGD. Edema and high-pressure pneumoperitoneum (high PNP) resulting 
from inflating the peritoneal cavity during laparoscopic surgery can also activate glia. There is more finger manipulation of the bowels with open surgery, but laparoscopic and robotic instruments use higher pressure over smaller areas than one's fingers. In laparoscopic operations, patient positioning and gravity are used for mass movement, but abdominal contents are exposed to increased serosa pressure from carbon dioxide insufflation. In addition to such high PNP, edema from intravenous fluids causes swelling and stretch of glia to activate them (Cooke et al., 2003; Christofi et al., 2004; Alcaino et al., 2017). Mechanogated channels are activated by such abnormal mechanical stimulation of the bowels during intestinal surgery-The types of channels involved are under investigation, but so far, the type of channel(s) linked to glial mechanosensation remain elusive. Candidate channels include various transient receptor potential channels, Piezo 1, 2 channels, connexin hemichannels, pannexin channels, P2X7 channels and Aquaporin channels (Kirischuk, 2008; Alcaino et al., 2017; Suchyna, 2017; Wang et al., 2017). A better understanding of these channels in enteric glia is important in developing better strategies to prevent POI and POGD.

High Vs. Low-Pressure Pneumoperitoneum Despite lower incidence of POI with a minimal invasive approach compared with open surgery (laparotomy) (Behm and Stollman, 2003; Bragg et al., 2015) and improvements seen with the implementation of CERAS protocols, this technique requires carbon dioxide $\left(\mathrm{CO}_{2}\right)$ and higher abdominal pressure in order to enhance laparoscopic visualization for surgery. These factors also contribute to POI and POGD and it can adversely affect the patient's homeostasis, leading to cardiovascular and respiratory systems changes, as well as a decrease in perfusion of abdominal organs (Bragg et al., 2015; Schietroma et al., 2016). High-pressure pneumoperitoneum (PNP), may cause systemic inflammation and affect the immune response in the early postoperative period (Schietroma et al., 2013; Schietroma et al., 2016; Vasdev et al., 2018; Rohloff et al., 2019). In order to overcome such adverse effects, low $\mathrm{CO}_{2}$ PNP pressure could potentially be used to reduce the risk of POI and POGD by reducing postoperative inflammatory response (circulating levels of inflammatory mediators or intestinal inflammation) and immune suppression.

It is hypothesized that the use of low PNP would reduce intestinal inflammation, protect against smooth muscle dysfunction, POI and POGD. To date, no clinical trials have tested whether low-pressure pneumoperitoneum is protective against intestinal and systemic inflammation, POI and POGD. Our ongoing research has shown that intestinal glial cells are very sensitive to physiologic mechanical forces such as those occurring during peristalsis or excessive forces such as occur during surgical manipulation. During laparoscopic surgery, excessive external mechanical forces generated by high-pressure pneumoperitoneum may overcome the autoregulation capacity of the intestinal glia, and the constant increased intra-abdominal pressure (IAP) which result in bowel compression would induce a reactive glial phenotype. Therefore, one could expect that the reactive glia phenotype may be responsible for some of the common postoperative complications in patients undergoing laparoscopic

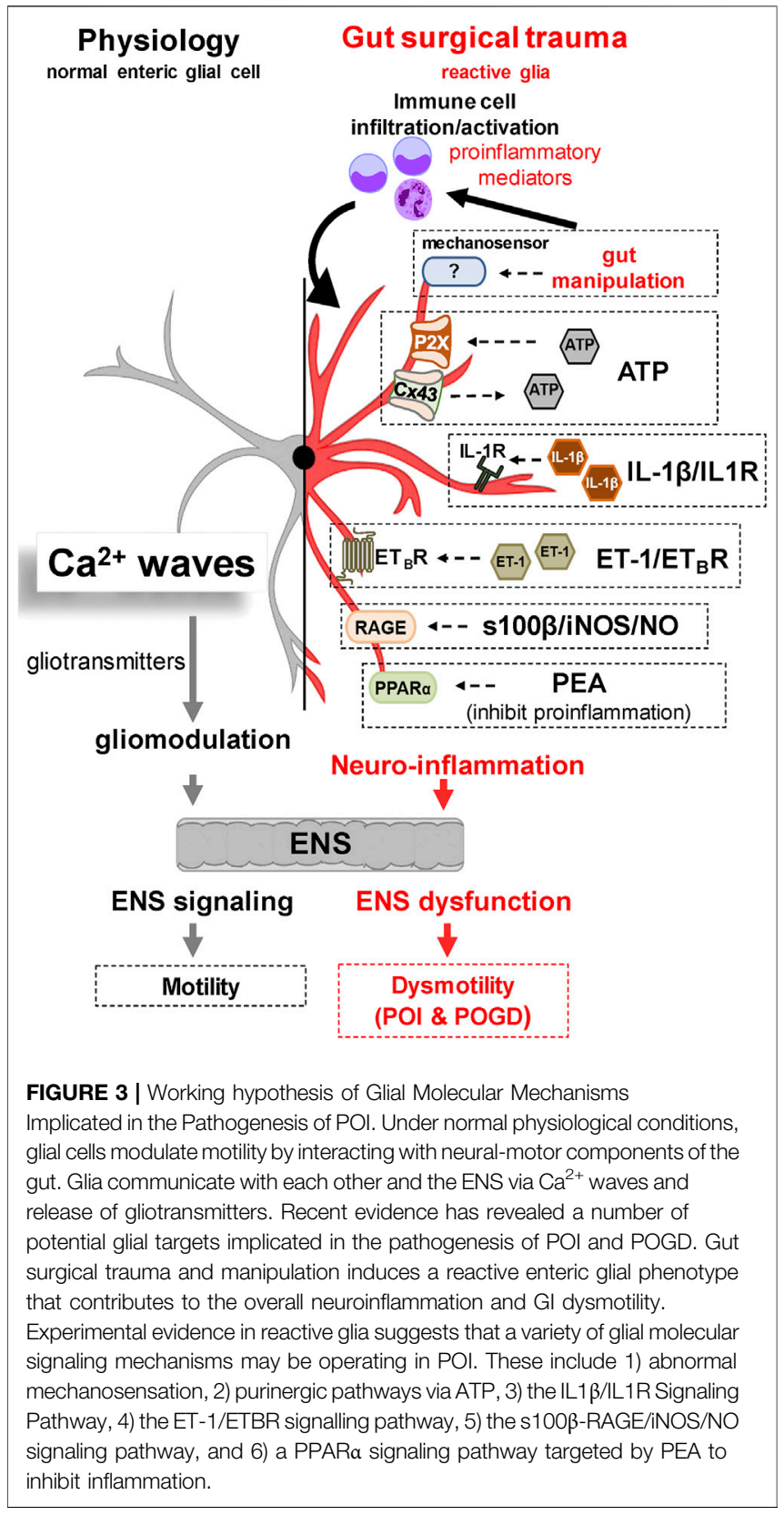

abdominal surgery (Liñán-Rico et al., 2016; Gulbransen and Christofi, 2018). In a recent retrospective study, lower pneumoperitoneum pressures were associated with a reduced incidence of POI and LOS in 400 patients undergoing roboticassisted radical prostatectomy (Rohloff et al., 2019). Similarly, a decreased postoperative inflammatory response and attenuation of postoperative immunosuppression/human leukocyte antigen-DR receptor expression were reported in patients undergoing laparoscopic Nissen fundoplication (LNF) with low pneumoperitoneum pressures (Schietroma et al., 2013).

Reactive glia together with other cells in the gut muscularis externa (i.e., immune cell infiltration, neutrophils, monocytes, resident macrophages and smooth muscle cells) produce and 
release pro-inflammatory mediators and activate pathogenic mechanisms to induce POI and POGD. Diverse pathways and mechanisms in reactive glia such as mechanogated channels, IL$1 \beta$ signaling, growth factors, s100 $\beta$ signaling, ATP signaling, Cx43 hemichannels, PPAR alpha receptors, and chemical messengers like nitric oxide (NO) can alter ENS function, induce enteric neuropathy, and cause POI. These are potential novel glial targets for future drug development that have been described in a recent review in IBD (2016) (Ochoa-Cortes et al., 2016) and a commentary in Gastroenterology by Gulbransen and Christofi (2018). Therefore, they will only be given a brief mention here. Potential pathogenic mechanisms targeted in preclinical studies for POI are shown in Figure 3.

\section{Edema}

Edema alone can decrease intestinal contractile activity (Uray et al., 2006; Chu et al., 2012). During abdominal surgery and surgical trauma, edema results in increased stretch of intestinal smooth muscle cells that was shown to down-regulate MLC phosphorylation (Chu et al., 2013). Therefore edema in the gut wall and increased intestinal wall stress (Cox et al., 2008) can also cause smooth muscle dysfunction after intestinal surgical trauma.

\section{EXPERIMENTAL TARGETS FOR THERAPY ON ENTERIC GLIA}

\section{IL-1 $\beta / I L 1 R$ Signaling in Glia}

Interleukin-1 $\beta$ activation of interleukin-1 receptor (IL-1R) in enteric glia is a potential pathogenic mechanism in experimental postoperative ileus induced by gut surgical manipulation and trauma. In pre-clinical studies, Sven Wehner's group identified IL- $1 \beta$ and IL- $1 \mathrm{R}$ signaling in enteric glia as a potential contributing mechanism to GI motility disruption and POI. These findings were supported by the fact that the IL- $1 \beta$ receptor antagonist "anakinra," was effective in reducing inflammation and POI. Antagonist drugs at IL-1R such as anakinra are in clinical use for rheumatoid arthritis and their therapeutic benefit could be tested in POI and POGD (Stoffels et al., 2014). A recent study showed that the "absent in melanoma 2" (AIM2) inflammasome-derived IL- $1 \beta$ induces POI in mice. IL$1 \beta$ production depends on AIM2 inflammasome formation and the microbiome. Targeting this pathway might also be a promising target to prevent POI in surgical patients (Hupa et al., 2019).

\section{s100 $\beta$ Protein in Glia}

Glial s100 $\beta$ protein is a marker of enteric glia but is also involved in inflammation caused by pathogenic bacteria such as infection with Clostridium difficile and it involved in UC and celiac diseases (Esposito et al., 2007). Bacterial products activate the glial toll-like receptor - 4 via the s100 $\beta$-RAGE/iNOS/NO signaling pathway via nuclear transcription factor $\mathrm{nfkB}$. This pathway is involved in ENS neural dysfunction. RAGE inhibitors or drugs that interfere with different components of the pathway, such as a NOS inhibitor L-NMMA that demonstrated efficacy in a clinical trial could be tested in POI and POGD (Galasko et al., 2014).

\section{PPARa Receptors}

Targeting PPARa receptors with palmitoylethanolamide (PEA), a receptor agonist, can inhibit pro-inflammatory responses in reactive enteric glia in pre-clinical IBD models. Testing PEA in a clinical trial for POI, a disease associated with acute inflammation of the muscularis externa may be possible since it is available as a nutritional supplement for the relief of intestinal symptoms of IBD. One caveat is that PEA also activates other receptors in the gut and a more selective PPAR $a$ agonist would be preferred (Esposito et al., 2014).

\section{Endothelin-B Receptor Signaling in Glia}

Our recent work supports the novel hypothesis that glial endothelin-1 (ET-1)/endothelin-B receptor $\left(\mathrm{ET}_{\mathrm{B}} \mathrm{R}\right)$ signaling in enteric glia disrupts motility and it contributes to the pathogenesis of POI and POGD in the context of intestinal inflammation (Christofi et al., 2018; Mazzotta et al., 2019).

Pathogenic mechanism(s) under investigation include glial hypersensitivity to $\mathrm{ET}-1 / \mathrm{ET}_{\mathrm{B}} \mathrm{R}$ signaling, induction of a reactive glial phenotype, enteric gliosis, enteric neuropathy and ENS dysfunction, and specific alterations in neural-motor pathways. Ongoing studies in our laboratory supported by the National Institute of Diabetes, Digestive and Kidney Diseases (NIDDK) will investigate whether the glial ET-1/ET $\mathrm{B}$ signaling pathway is a potential novel therapeutic target in the prophylaxis against deleterious effects in glia, neurons and motility in POI and POGD.

Ongoing studies in our laboratory supported by NIH R01 DK113943 and R01 DK125809 are aimed to expand our current understanding of the pathogenic mechanisms in reactive glia linked to POI. Pathogenic targets of investigation include ATP purinergic signaling [or related nucleotides such as UTP, UDP, ADP] mediated through $\mathrm{P} 2 \mathrm{X}$ or $\mathrm{P} 2 \mathrm{Y}$ receptors on glia, endothelin-1/ET $\mathrm{B}_{\mathrm{B}}$ receptor signaling and IL1 $\beta / \mathrm{IL} 1 \mathrm{R}$ Signaling.

\section{DOES POSTOPERATIVE GASTROINTESTINAL TRACT DYSFUNCTION IMPACT LONG-TERM FUNCTIONAL RECOVERY AFTER SURGERY AND QUALITY OF LIFE IN THE PATIENT?}

Little is known about quality and functional recovery after surgery (Feldman et al., 2015). It is not clear if POGD has a downstream effect on long-term recovery and quality of life. The enteric nervous system, often called "the little brain," has similarities with the central nervous system "the big brain." It is possible to draw some parallels between neuroinflammatory disorders that affect these two organs, specifically POGD and POCD (postoperative cognitive dysfunction). For instance, we know that POCD is an important complication after surgery, especially in the elderly patient, with short term and long-term complications that significantly impact their quality of life (Steinmetz et al., 2009; Rundshagen, 2014). It is also possible and quite probable that POGD may represent short- and long- 
term complications during the acute phase involving inflammation, and long term after inflammation has resolved and the patient leaves the hospital. A recent study in neurogastroenterology and motility provided proof of concept, by showing for the first time that POI significantly decreases the quality of life at 3 and 6 months (QoL) (Peters et al., 2020). Therefore, it would be prudent to incorporate quality of life questionnaires in the CERAS protocols and extending the timeline to a longer postoperative period to uncover potential complications occurring after intestinal or systemic inflammation has resolved to further investigate long-term outcomes and mechanisms in POGD.

\section{COLORECTAL ENCHANCED RECOVERY AFTER SURGERY PROTOCOLS}

ERAS guidelines are evidence-based protocols designed to standardize medical care, accelerate patient recovery, attenuate surgical stress response, improve patients' outcomes and reduce the length of stay (LOS) and associated costs (Kehlet and Wilmore, 2008). ERAS involves a holistic, multimodal and articulate approach involving perioperative care.

Most of the Colorectal ERAS (CERAS) protocols combine 15-20 variables and a multidisciplinary group is required to coordinate each phase of the perioperative periods (Kehlet and Wilmore, 2008). Even though the relative contribution of each element to the utmost outcomes has not been determined, reduced stress response and accelerated recovery have been consistently reported in patients undergoing surgery within ERAS protocols (Varadhan et al., 2010; Kehlet and Joshi, 2017; Slim and Joris, 2017). In spite of the favorable perioperative outcomes reported in the first CERAS protocol in 2005, these guidelines were not widely implemented until recent years (Greco et al., 2014; Miller et al., 2014; Bakker et al., 2015; Nelson et al., 2016; Kehlet and Joshi, 2017; Pecorelli et al., 2017).

\section{Laparoscopic Surgery}

Minimally invasive techniques are the cornerstone of ERAS protocols. Initial pre-clinical and clinical trials showed an association between smaller incisions and minimal or gentle gut manipulation with reduced surgical trauma, inflammation, and GI dysfunction (Böhm et al., 1995; Kehlet, 1999; Novitsky et al., 2004; Mamidanna et al., 2012). A faster resolution of GI dysfunction and reduced length of hospital stay have been reported in patients undergoing laparoscopic surgery when compared to conventional open surgical approaches (Schwenk et al., 1998; Schwenk et al., 2005; Van Bree et al., 2011; Mazzotta et al., 2020). However, when the open surgical approach is combined with ERAS protocols, POI incidence may be comparable between open and laparoscopic groups (Lei et al., 2015). Nevertheless, a recent report suggests that in the context of ERAS, laparoscopic techniques are associated with better immunologic response and shorter duration of POI (Wang et al., 2018).

\section{Early Feeding and Nasogastric Tube}

Nasogastric (NG) tube insertion along with liberal parenteral hydration were routinely indicated during the postoperative period of GI surgery. Traditionally, the common practice involved leaving the GI tract to rest after surgery expecting faster healing. Therefore, the return of GI function was mandatory before the resumption of enteric nutrition (Verma and Nelson, 2007). However, little evidence supported these methods. In contrast, a growing body of evidence suggested that early feeding was associated with a significant reduction in postoperative complications and length of hospital stay (Lewis et al., 2001; Andersen et al., 2006; Lewis et al., 2009; Zhuang et al., 2013).

\section{Multimodal Analgesia}

Postoperative pain management after abdominal surgery may be challenging for health care providers. Moreover, early pain control and GI functional recovery are both essential in CERAS protocols. Despite being effective analgesics, reduced GI motility is commonly reported in patients receiving opioids for postoperative pain management (Viscusi et al., 2009).

Multimodal analgesia combines regional analgesia, nonopioid analgesics [acetaminophen, nonsteroidal antiinflammatory drug (NSAID) or cyclooxygenase (COX)-2 specific inhibitor], lidocaine infusions, gabapentinoids and ketamine. Numerous studies have shown the opioid-sparing effect of this approach resulted in an accelerated GI recovery and improved outcomes. However, an optimal combination of these elements has not yet been elucidated (Geltzeiler et al., 2014; Miller et al., 2014; Helander et al., 2017; Wick et al., 2017).

\section{Regional Analgesia}

Thoracic Epidural

Thoracic epidural accelerates peristalsis by blocking pain afferents and efferent sympathetic inhibitory nerves. Epidural blocks are commonly used in patients undergoing open and complex abdominal surgeries (Gustafsson et al., 2012). In 2016, a Cochrane review of patients undergoing abdominal surgery reported a relevant association between epidural analgesia with an accelerated return of flatus and bowel movements (Khan et al., 2013; Guay et al., 2016). However, some reports suggested that this technique may also increase LOS after laparoscopic abdominal procedures under ERAS protocols (Nimmo and Harrington, 2014; Hübner et al., 2015; Borzellino et al., 2016).

\section{Transverse Abdominis Plane Block}

Transverse abdominis plane block (TAP block) is an effective alternative in patients undergoing abdominal surgeries. Torgeson et al. (2018) studied the non-analgesic outcomes in 78 patients undergoing open and laparoscopic colorectal surgery under general anesthesia, receiving either a TAP or an epidural block. A significant reduction in LOS (2.8 vs. 3.3 days, $p=$ 0.026 ) was reported in the TAP block group with comparable results in GI recovery variables. Of note, the incidence of 
postoperative nausea and vomiting was higher in the TAP block group (31.7 vs. $13.5 \%$; $p=0.057$ ) (Torgeson et al., 2018).

\section{Nonsteroidal Anti-Inflammatory Drugs and Acetaminophen}

Nonsteroidal anti-inflammatory drugs (NSAIDs) such as ketorolac and ibuprofen, mainly block the cyclooxygenase (COX) enzyme inhibiting the prostaglandin biosynthesis with subsequent decreased pain receptor activation. Similarly, an opioid-sparing effect and decreased opioid-related side effects have been reported after NSAIDs use (Elia et al., 2005; Straube et al., 2005).

Pre-clinical data suggests that eicosanoids play a key role in the development of POI, with NSAIDs being potentially able to accelerate GI recovery (Cheng et al., 1996; Kalff et al., 1998). However, NSAIDs' analgesic ceiling and clinically relevant side effects (i.e., platelets dysfunction, GI bleeding, and renal dysfunction) may limit their use in patients with GI tract pathologies (Strom et al., 1996). Moreover, selective COX-2 inhibitors have a potent analgesic and anti-inflammatory effect but, its use in this patient setting has been associated with higher rates of anastomotic leak (Klein et al., 2011; Rushfeldt et al., 2011). In contrast, acetaminophen may be an acceptable alternative therapy for pain management (Apfel et al., 2013). Oral, intravenous and rectal formulations are available.

\section{Adjuvant Analgesic Medications}

Lidocaine infusion is commonly known for its anti-inflammatory properties and opioid-sparing effect (Knotkova and Pappagallo, 2007; Dunn and Durieux, 2017). In addition to reduced postoperative pain scores, lidocaine infusion may improve GI recovery and shorten LOS after open abdominal surgeries (Sun et al., 2012). Other adjuvant agents such as gabapentin and ketamine, are widely known by their anti-hyperalgesic effect and a subsequent reduction in opioid consumption that potentially decreases the incidence and duration of POGD (Bell et al., 2006; Hurley et al., 2006; Mishriky et al., 2015).

\section{Peripherally Acting $\mu$-Opioid Receptor Antagonist (PAM-OR)}

Autonomic GI dysfunction is a well-known side effect of $\mu$-receptor agonists. Opioids' effects on central and intestinal $\mu$-receptors may result in impaired GI motility. Some pharmacologic agents decrease the incidence and duration of POI by selectively blocking the intestinal (i.e., peripheral) $\mu$-receptor (Sobczak et al., 2014). Alvimopan, an oral PAMOR, has been approved by the Food and Drug Administration (FDA) for more than a decade to prevent opioid-induced constipation and POI. There is an important body of evidence indicating that Alvimopan enhances GI recovery in patients who received high doses of opioids after open abdominal surgery (Delaney et al., 2007; Vaughan-Shaw et al., 2012). However, in light of ERAS protocols involving reduced opioids requirement, the usefulness of Alvimopan in minimally-invasive colorectal surgery has been recently questioned (Keller et al., 2016).

\section{Bowel Preparation}

Mechanical bowel preparation with oral antibiotics (MBP-OAB) is commonly indicated to prevent surgical site infection (SSI), anastomotic leak and ileus after elective colorectal surgery (Kiran et al., 2015; Morris et al., 2015; Holubar et al., 2017). However, a recent randomized clinical trial by Koskenvuo et al. (2019) reported that $\mathrm{MBP}-\mathrm{AOB}$ does not reduce SSI or the overall morbidity (including POI) when compared to no bowel preparation $(\mathrm{NBP})$ in patients undergoing elective colonic surgery.

\section{Perioperative Fluid Management}

The gut is highly susceptible to interstitial edema. Excessive perioperative fluid administration may lead to edema contributing to POI and delay in GI recovery, delay in the gut's anastomotic healing and delay in hospital discharge (Gan et al., 2002; Holte et al., 2002; Lobo et al., 2002; Moore-Olufemi et al., 2005; Nisanevich et al., 2005; Uray et al., 2006; Schnüriger et al., 2011). However, in the context of CERAS programs with more conservative fluid therapies, the effects of edema may be importantly attenuated (Srinivasa et al., 2013; Gómez-Izquierdo et al., 2015; Gómez-Izquierdo et al., 2017).

\section{Supportive Treatment and Symptom Control}

Supportive treatment and symptom control are paramount during POGD management. The first step is to rule out any acute intra-abdominal condition or other surgical complications. Serial radiographic imaging and computed tomography (CT) scan should be considered (Sandrasegaran and Maglinte, 2005). Supportive care may include the removal of any potential triggers such as opioids and fluid overload. Moreover, bowel rest with NG tube insertion may be considered for gastric decompression and pulmonary aspiration risk (Adiamah and Lobo, 2020).

\section{CURRENT THERAPIES LISTED IN CLINICAL TRIALS.GOV}

A search of Clinical Trials.gov identified 125 ongoing clinical trials, with many in advanced clinical trials (Phase III or Phase IV trials), including new or old drugs, herbal medications, acupuncture and Vagus Nerve Stimulation (VNS). Methylnaltrexone and Naldemedine are peripheral acting $\mu$-opioid antagonists to prevent opioid induced slow transit constipation. Simethiocone is in a Phase IV clinical trial for POI that acts as an anti-bloating and anti-flatulence medication by reducing the surface tension of the gas. Ulimovelin is a ghrelin agonist being tested as a prokinetic agent in a new Phase III clinical trial. Ulimorelin was shown to be ineffective in preventing POI in an earlier large RCT (Shaw et al., 2013). Historically, prokinetic agents have been commonly 
used to treat POI. However, a large body of evidence has shown little or no benefits after administrating neostigmine, erythromycin, or metoclopramide in patients with impaired GI function (Myrhöj et al., 1988; Tollesson et al., 1991; Smith et al., 2000). Lidocaine infusion is in a Phase II clinical trial for prophylaxis of POGD for radical systectomy. Beet root juice and TU-100 are examples of herbal medications in Phase II trials for POI and POGD. Drinking coffee and nicotine chewing gum are other approaches under investigation. Chewing gum was traditionally known to expedite GI recovery after abdominal surgery ( $\mathrm{Li}$ et al., 2013). However, most of the studies supporting this effect were published before the implementation of early postoperative feeding as part of the ERAS protocols (Ho et al., 2014). The effects of chewing gum are described in a systematic review (Short et al., 2015).

Caffeine is widely known as a stimulant to colonic motor activity in animals and humans (Rao et al., 1998). Clinical trials have shown that caffeinated drinks decrease the time to flatus and first bowel movement and if given as soon as $2 \mathrm{~h}$ after surgery, it may accelerate GI recovery and reduce LOS (Müller et al., 2012; Dulskas et al., 2015; Göymen et al., 2017; Kane et al., 2020).

\section{CONCLUSION}

Our review focused on recent advances and understanding in pathogenic mechanisms, treatment strategies, pipeline drugs and ongoing clinical trials and approved medications for those targets for POI and POGD. Further clinical studies on $5 \mathrm{HT}_{4} \mathrm{R}$ agonists and vagal nerve stimulation are required to establish their usefulness as novel therapies, and more work needs to be done of short and long term impact of gut surgical manipulation on patient outcomes. A key target of investigation should be to pinpoint the triggering mechanism(s) in various cells in the intestinal wall, and better understand the dynamic interactions between various cells implicated in the disease. Enteric glial cells (EGCs) are abundant in the gut and they may play a role in the pathophysiology of POI and POGD. Our review provides some examples of how targeting different cells in the gut wall, can potentially identify novel therapeutic targets for POI and POGD. Despite the implementation of enhanced recovery protocols for GI surgeries, there is still significant POI and POGD associated with prolonged hospitalizations, and increased morbidity and healthcare costs. We cannot deny that significant progress has been made with ERAS protocols and other advances in the field to reduce the incidence and overall morbidity associated with this iatrogenic disorder. Novel therapies in the pipeline offer some hope for better treatments,

\section{REFERENCES}

Adiamah, A., and Lobo, D. N. (2020). "Postoperative ileus: prevention and treatment," in Enhanced recovery after surgery. New York, NY: Springer International Publishing, 249-257. but a better understanding of the pathogenic mechanism(s) of POI is required to develop better therapeutic strategies (Collins et al., 2016). As food for thought, the NIH recently published its strategic plan. In that document, NIH reaffirmed its strong commitment for basic scientific discovery noting that many of the most important medical advances trace back to basic research, which had no explicit link [NIH, NIH-Wide Strategic Plan (www. nih.gov/about-nih/nih-wide-strategic-plan)]. Further research into basic mechanisms of immune/inflammatory cells (muscularis macrophages, dendritic cells, leukocytes, monocytes, mast cells), "reactive enteric glia", ICC's, intrinsic and extrinsic neural pathways, and the microbiome in the gut lumen is an essential step in developing novel treatment strategies, but a big hurdle is translatability of findings in animal models to humans. This will allow us to improve our CERAS protocols in the prophylaxis against POI and POGD.

\section{AUTHOR CONTRIBUTIONS}

FC is the corresponding author funded by NIH in the field of POI and POGD to study pathogenic mechanisms, and he proposed the "reactive glial hypothesis of POI in response to gut manipulation and mechanosensation during GI surgery" forwarded in the review. $\mathrm{EM}, \mathrm{EV}, \mathrm{JF}, \mathrm{AH}$, and $\mathrm{FC}$ contributed to the literature review, concepts, hypotheses and writing and formatting of the manuscript. EM is a Fellow in Anesthesiology and $\mathrm{AH}$ is a GI Surgeon, and they were responsible for writing the Clinical section on CERAS protocols.

\section{FUNDING}

FC is the recipient of grants R01 DK113943 and DK125809 from the National Institutes of Diabetes, Digestive and Kidney Diseases (NIDDK) on postoperative ileus.

\section{ACKNOWLEDGMENTS}

We wish to thank the Department of Anesthesiology for providing additional developmental funds to support studies on postoperative ileus. In addition, we would like to thank the members of our Clinical Research Team in the Anesthesiology Department at The Ohio State University for their support of our clinical studies on POI, in scheduling and consenting patients to participate in the studies, providing regulatory support, and for procurement of viable surgical specimens from GI surgeries to study pathogenic mechanisms of postoperative ileus.

Alcaino, C., Farrugia, G., and Beyder, A. (2017). "Mechanosensitive piezo channels in the gastrointestinal tract," in Current topics in membranes. Cambridge, MA: Academic Press, 219-244.

Andersen, H. K., Lewis, S. J., and Thomas, S. (2006). Early enteral nutrition within $24 \mathrm{~h}$ of colorectal surgery versus later commencement of feeding for postoperative complications. Cochrane Database Syst. Rev. 18 (4), CD004080. doi:10.1002/14651858.CD004080.pub2 
Apfel, C. C., Turan, A., Souza, K., Pergolizzi, J., and Hornuss, C. (2013). Intravenous acetaminophen reduces postoperative nausea and vomiting: a systematic review and meta-analysis. Pain 154, 677-689. doi:10.1016/j.pain. 2012.12.025

Böhm, B., Milsom, J. W., and Fazio, V. W. (1995). Postoperative intestinal motility following conventional and laparoscopic intestinal surgery. Arch. Surg. 130, 415-419. doi:10.1001/archsurg.1995.01430040077017

Bakker, N., Cakir, H., Doodeman, H. J., and Houdijk, A. P. J. (2015). Eight years of experience with enhanced recovery after surgery in patients with colon cancer: impact of measures to improve adherence. Surgery 157, 1130-1136. doi:10.1016/j.surg.2015.01.016

Bauer, A. J., and Boeckxstaens, G. E. (2004). Mechanisms of postoperative ileus. Neurogastroenterol. Motil. 16, 54-60. doi:10.1111/j.1743-3150.2004.00558.x

Beattie, D. T., Armstrong, S. R., Vickery, R. G., Tsuruda, P. R., Campbell, C. B., Richardson, C., et al. (2011). The pharmacology of TD-8954, a potent and selective 5-HT4 receptor agonist with gastrointestinal prokinetic properties. Front. Pharmacol. 2, 25. doi:10.3389/fphar.2011.00025

Behm, B., and Stollman, N. (2003). Postoperative ileus: etiologies and interventions. Clin. Gastroenterol. Hepatol. 1, 71-80. doi:10.1053/cgh.2003.50012

Bell, R. F., Dahl, J. B., Moore, R. A., and Kalso, E. A. (2006). Perioperative ketamine for acute postoperative pain. Cochrane Database Syst. Rev. 25 (1), CD004603. doi:10.1002/14651858.cd004603.pub2.

Boelens, P. G., Heesakkers, F. F. B. M., Luyer, M. D. P., Van Barneveld, K. W. Y., De Hingh, I. H. J. T., Nieuwenhuijzen, G. A. P., et al. (2014). Reduction of postoperative ileus by early enteral nutrition in patients undergoing major rectal surgery: prospective, randomized, controlled trial. Ann. Surg. 259, 649-655. doi:10.1097/SLA.0000000000000288

Borzellino, G., Francis, N. K., Chapuis, O., Krastinova, E., Dyevre, V., and Genna, M. (2016). Role of epidural analgesia within an ERAS program after laparoscopic colorectal surgery: a review and meta-analysis of randomised controlled studies. Surg. Res. Pract. 2016, 7543684. doi:10.1155/2016/7543684

Bouras, E. P., Camilleri, M., Burton, D. D., and McKinzie, S. (1999). Selective stimulation of colonic transit by the benzofuran $5 \mathrm{HT} 4$ agonist, prucalopride, in healthy humans. Gut 44, 682-686. doi:10.1136/gut.44.5.682

Bragg, D., El-Sharkawy, A. M., Psaltis, E., Maxwell-Armstrong, C. A., and Lobo, D. N. (2015). Postoperative ileus: Recent developments in pathophysiology and management. Clin. Nutr. 34, 367-376. doi:10.1016/j.clnu.2015.01.016

Cailotto, C., Costes, L. M. M., van der Vliet, J., van Bree, S. H. W., van Heerikhuize, J. J., Buijs, R. M., et al. (2012). Neuroanatomical evidence demonstrating the existence of the vagal anti-inflammatory reflex in the intestine. Neurogastroenterol. Motil. 24, 191-200. doi:10.1111/j.1365-2982.2011.01824.x

Calvert, J. W., Coetzee, W. A., and Lefer, D. J. (2010). Novel insights into hydrogen sulfide-mediated cytoprotection. Antioxid. Redox Signal. 12, 1203-1217. doi:10. 1089/ars.2009.2882

Chapman, M., Deane, A. M., Jones, K. L., Barnes, C., Nguyen, D., and Almansa, C. (2018). Efficacy and safety OF TAK-954 IN critically ill patients with enteral feeding intolerance: a randomized phase 2A clinical trial. Gastroenterology 154, S158. doi:10.1016/S0016-5085(18)30942-9

Cheng, G., Cassissi, C., Drexler, P. G., Vogel, S. B., Sninsky, C. A., and Hocking, M. P. (1996). Salsalate, morphine, and postoperative ileus. Am. J. Surg. 171, 85-89. doi:10.1016/S0002-9610(99)80079-8

Chow, A. K., and Gulbransen, B. D. (2017). Potential roles of enteric glia in bridging neuroimmune communication in the gut. Am. J. Physiol. Liver Physiol. 312, G145-G152. doi:10.1152/ajpgi.00384.2016

Christofi, F. L., Kim, M., Wunderlich, J. E., Xue, J., Suntres, Z., Cardounel, A., et al. (2004). Endogenous adenosine differentially modulates 5-hydroxytryptamine release from a human enterochromaffin cell model. Gastroenterology 127, 188-202. doi:10.1053/j.gastro.2004.04.070

Christofi, F. L., Mazzotta, E., Villalobos-Hernandez, E. C., Blakeney, B., Grants, I., Schneider, R., et al. (2018). Glial edothelin ETB receptor signaling my inhibit intestinal peristaltic activity. Neurogastroenterol. Motil. 30, e13443. doi:10.1111/ nmo. 13443

Chu, J., Miller, C. T., Kislitsyna, K., Laine, G. A., Stewart, R. H., Cox, C. S., et al. (2012). Decreased myosin phosphatase target subunit 1(MYPT1) phosphorylation via attenuated rho kinase and zipper-interacting kinase activities in edematous intestinal smooth muscle. Neurogastroenterol. Motil. 24, 257. doi:10.1111/j.1365-2982.2011.01855.x

Chu, J., Pham, N. T., Olate, N., Kislitsyna, K., Day, M. C., LeTourneau, P. A., et al. (2013). Biphasic regulation of myosin light chain phosphorylation by p21- activated kinase modulates intestinal smooth muscle contractility. J. Biol. Chem. 288, 1200-1213. doi:10.1074/jbc.M112.370718

Collins, F. S., Anderson, J. M., Austin, C. P., Battey, J. F., Birnbaum, L. S., Briggs, J. P., et al. (2016). Basic science: bedrock of progress. Science 351, 1405. doi:10. 1126/science.351.6280.1405-a

Cooke, H. J., Wunderlich, J., and Christofi, F. L. (2003). "The force be with you": ATP in gut mechanosensory transduction. News Physiol. Sci. 18, 43-49. doi:10. 1152/nips.01411.2002

Cox, C. S., Radhakrishnan, R., Villarrubia, L., Xue, H., Uray, K., Gill, B. S., et al. (2008). Hypertonic saline modulation of intestinal tissue stress and fluid balance. Shock 29, 598-602. doi:10.1097/SHK.0b013e318157eba7

de Jonge, W. J., van der Zanden, E. P., The, F. O., Bijlsma, M. F., van Westerloo, D. J., Bennink, R. J., et al. (2005). Stimulation of the vagus nerve attenuates macrophage activation by activating the Jak2-STAT3 signaling pathway. Nat. Immunol. 6, 844-851. doi:10.1038/ni1229

Delaney, C. P., Wolff, B. G., Viscusi, E. R., Senagore, A. J., Fort, J. G., Du, W., et al. (2007). Alvimopan, for postoperative ileus following bowel resection: a pooled analysis of phase III studies. Ann. Surg. 245, 355-363. doi:10.1097/01.sla. 0000232538.72458 .93

Deng, G., Wong, W. D., Guillem, J., Chan, Y., Affuso, T., Yeung, K. S., et al. (2013). A phase II, randomized, controlled trial of acupuncture for reduction of postcolectomy ileus. Ann. Surg Oncol. 20, 1164-1169. doi:10.1245/s10434012-2759-7

Deng, J.-J., Lai, M.-Y., Tan, X., and Yuan, Q. (2019). Acupuncture protects the interstitial cells of cajal by regulating miR-222 in a rat model of post-operative ileus. Acupunct. Med. 37, 125-132. doi:10.1177/0964528419829755

Deng, J., Yang, S., Yuan, Q., Chen, Y., Li, D., Sun, H., et al. (2017). Acupuncture ameliorates postoperative Ileus via IL-6-miR-19a-KIT axis to protect interstitial cells of cajal. Am. J. Chin. Med. 45, 737-755. doi:10.1142/S0192415X17500392

Docsa, T., Bhattarai, D., Sipos, A., Wade, C. E., Cox, C. S., and Uray, K. (2020). CXCL1 is upregulated during the development of ileus resulting in decreased intestinal contractile activity. Neurogastroenterol. Motil. 32, e13757. doi:10. $1111 /$ nmo.13757

Dulskas, A., Klimovskij, M., Vitkauskiene, M., and Samalavicius, N. E. (2015). Effect of coffee on the length of postoperative ileus after elective laparoscopic left-sided colectomy: a randomized, prospective single-center study. Dis. Colon Rectum 58, 1064-1069. doi:10.1097/DCR.0000000000000449

Dunn, L. K., and Durieux, M. E. (2017). Perioperative use of intravenous lidocaine. Anesthesiology 126, 729-737. doi:10.1097/ALN.0000000000001527

Ekundi-Valentim, E., Mesquita, F. P., Santos, K. T., de Paula, M. A., Florenzano, J., Zanoni, C. I., et al. (2013). A comparative study on the anti-inflammatory effects of single oral doses of naproxen and its hydrogen sulfide (H2S)-releasing derivative ATB-346 in rats with carrageenan-induced synovitis. Med. Gas Res. 3, 24. doi:10.1186/2045-9912-3-24

Elia, N., Lysakowski, C., and Tramè, M. R. (2005). Does Multimodal Analgesia with acetaminophen, nonsteroidal antiinflammatory drugs, or selective cyclooxygenase- 2 inhibitors and patient-controlled analgesia morphine offer advantages over morphine alone? meta-analyses of randomized trials. Anesthesiology 103, 1296-1304. doi:10.1097/00000542-200512000-00025

Esposito, G., Capoccia, E., Turco, F., Palumbo, I., Lu, J., Steardo, A., et al. (2014). Palmitoylethanolamide improves colon inflammation through an enteric glia/ toll like receptor 4-dependent PPAR-a activation. Gut 63, 1300-1312. doi:10. 1136/gutjnl-2013-305005

Esposito, G., Cirillo, C., Sarnelli, G., De Filippis, D., D’Armiento, F. P., Rocco, A., et al. (2007). Enteric glial-derived S100B protein stimulates nitric oxide production in celiac disease. Gastroenterology 133, 918-925. doi:10.1053/j. gastro.2007.06.009

Evans, B., Clark, W. K., Moore, D. J., and Whorwell, P. J. (2007). Tegaserod for the treatment of irritable bowel syndrome and chronic constipation. Cochrane Database Syst. Rev. 17 (4), CD003960. doi:10.1002/14651858.CD003960.pub3

Fang, J. F., Fang, J. Q., Shao, X. M., Du, J. Y., Liang, Y., Wang, W., et al. (2017). Electroacupuncture treatment partly promotes the recovery time of postoperative ileus by activating the vagus nerve but not regulating local inflammation. Sci. Rep. 7, 1-14. doi:10.1038/srep39801

Farro, G., Stakenborg, M., Gomez-Pinilla, P. J., Labeeuw, E., Goverse, G., Di Giovangiulio, M., et al. (2017). CCR2-dependent monocyte-derived macrophages resolve inflammation and restore gut motility in postoperative ileus. Gut 66, 2098-2109. doi:10.1136/gutjnl-2016-313144 
Feldman, L. S., Lee, L., and Fiore, J. (2015). What outcomes are important in the assessment of enhanced recovery after surgery (ERAS) pathways? J. Can. Anesth. 62, 120-130. doi:10.1007/s12630-014-0263-1

Fettucciari, K., Ponsini, P., Gioè, D., Macchioni, L., Palumbo, C., Antonelli, E., et al. (2017). Enteric glial cells are susceptible to Clostridium difficile toxin B. Cell. Mol. Life Sci. 74, 1527-1551. doi:10.1007/s00018-016-2426-4

Fornai, M., van den Wijngaard, R. M., Antonioli, L., Pellegrini, C., Blandizzi, C., and de Jonge, W. J. (2018). Neuronal regulation of intestinal immune functions in health and disease. Neurogastroenterol. Motil. 30, e13406. doi:10.1111/nmo.13406

Gómez-Izquierdo, J. C., Feldman, L. S., Carli, F., and Baldini, G. (2015). Metaanalysis of the effect of goal-directed therapy on bowel function after abdominal surgery. Br. J. Surg. 102, 577-589. doi:10.1002/bjs.9747

Gómez-Izquierdo, J. C., Trainito, A., Mirzakandov, D., Stein, B. L., Liberman, S., Charlebois, P., et al. (2017). Goal-directed fluid therapy does not reduce primary postoperative ileus after elective laparoscopic colorectal surgery: a randomized controlled trial. Anesthesiology 127, 36-49. doi:10.1097/ALN. 0000000000001663

Göymen, A., Şimşek, Y., Özkaplan, Ş. E., Özdurak, H. İ., Akpak, Y. K., Semiz, A., et al. (2017). Effect of gum chewing and coffee consumption on intestinal motility in caesarean sections. J. Clin. Anal. Med. 8, 411-415. doi:10.4328/ JCAM.4901

Galasko, D., Bell, J., Mancuso, J. Y., Kupiec, J. W., Sabbagh, M. N., Van Dyck, C., et al. (2014). Clinical trial of an inhibitor of RAGE-Ab interactions in Alzheimer disease. Neurology 82, 1536-1542. doi:10.1212/WNL.0000000000000364

Gan, T. J., Soppitt, A., Maroof, M., El-Moalem, H., Robertson, K. M., Moretti, E., et al. (2002). Goal-directed intraoperative fluid administration reduces length of hospital stay after major surgery. Anesthesiology 97, 820-826. doi:10.1097/ 00000542-200210000-00012

Gelderblom, M., Melzer, N., Schattling, B., Göb, E., Hicking, G., Arunachalam, P., et al. (2014). Transient receptor potential melastatin subfamily member 2 cation channel regulates detrimental immune cell invasion in ischemic stroke. Stroke 45, 3395-3402. doi:10.1161/STROKEAHA.114.005836

Geltzeiler, C. B., Rotramel, A., Wilson, C., Deng, L., Whiteford, M. H., and Frankhouse, J. (2014). Prospective study of colorectal enhanced recovery after surgery in a community hospital. JAMA Surg. 149, 955-961. doi:10. 1001/jamasurg.2014.675

Goldstein, J. L., Matuszewski, K. A., Delaney, C. P., Senagore, A., Chiao, E. F., Shah, M., et al. (2007). Inpatient economic burden of postoperative ileus associated with abdominal surgery in the United States. $P$ and $T$ 32, 82-90.

Gomez-Pinilla, P. J., Binda, M. M., Lissens, A., Di Giovangiulio, M., van Bree, S. H., Nemethova, A., et al. (2014). Absence of intestinal inflammation and postoperative ileus in a mouse model of laparoscopic surgery. Neurogastroenterol. Motil. 26, 1238-1247. doi:10.1111/nmo.12376

Gong, J., Xie, Z., Zhang, T., Gu, L., Yao, W., Guo, Z., et al. (2016). Randomised clinical trial: prucalopride, a colonic pro-motility agent, reduces the duration of post-operative ileus after elective gastrointestinal surgery. Aliment. Pharmacol. Ther. 43, 778-789. doi:10.1111/apt.13557

Goverse, G., Stakenborg, M., and Matteoli, G. (2016). The intestinal cholinergic anti-inflammatory pathway. J. Physiol. 594, 5771-5780. doi:10.1113/JP271537

Grainger, J. R., Wohlfert, E. A., Fuss, I. J., Bouladoux, N., Askenase, M. H., Legrand, F., et al. (2013). Inflammatory monocytes regulate pathologic responses to commensals during acute gastrointestinal infection. Nat. Med. 19, 713-721. doi:10.1038/nm.3189

Greco, M., Capretti, G., Beretta, L., Gemma, M., Pecorelli, N., and Braga, M. (2014). Enhanced recovery program in colorectal surgery: a meta-analysis of randomized controlled trials. World J. Surg. 38, 1531-1541. doi:10.1007/ s00268-013-2416-8

Grubišić, V., McClain, J. L., Fried, D. E., Grants, I., Rajasekhar, P., Csizmadia, E., et al. (2020). Enteric glia modulate macrophage phenotype and visceral sensitivity following inflammation. Cell Rep. 32, 108100. doi:10.1016/j.celrep. 2020.108100

Guay, J., Nishimori, M., and Kopp, S. L. (2016). Epidural local anesthetics versus opioid-based analgesic regimens for postoperative gastrointestinal paralysis, vomiting, and pain after abdominal surgery: a cochrane review. Anesth. Analg. 123, 1591-1602. doi:10.1213/ANE.0000000000001628

Gulbransen, B. D., and Christofi, F. L. (2018). Are we close to targeting enteric glia in gastrointestinal diseases and motility disorders? Gastroenterology 155, 245-251. doi:10.1053/j.gastro.2018.06.050
Gustafsson, U. O., Scott, M. J., Schwenk, W., Demartines, N., Roulin, D., Francis, N., et al. (2012). Guidelines for perioperative care in elective colonic surgery: enhanced recovery after surgery (ERAS ${ }^{\varpi}$ ) society recommendations. Clin. Nutr. 31, 783-800. doi:10.1016/j.clnu.2012.08.013

Hübner, M., Blanc, C., Roulin, D., Winiker, M., Gander, S., and Demartines, N. (2015). Randomized clinical trial on epidural versus patient-controlled analgesia for laparoscopic colorectal surgery within an enhanced recovery pathway. Ann. Surg. 261, 648-653. doi:10.1097/SLA.0000000000000838

Haraguchi, K., Kawamoto, A., Isami, K., Maeda, S., Kusano, A., Asakura, K., et al. (2012). TRPM2 contributes to inflammatory and neuropathic pain through the aggravation of pronociceptive inflammatory responses in mice. J. Neurosci. 32, 3931-3941. doi:10.1523/JNEUROSCI.4703-11.2012

Hedrick, T. L., McEvoy, M. D., Mythen, M. M. G., Bergamaschi, R., Gupta, R., Holubar, S. D., et al. (2018). American society for enhanced recovery and perioperative quality initiative joint consensus statement on postoperative gastrointestinal dysfunction within an enhanced recovery pathway for elective colorectal surgery. Anesth. Analg. 126, 1896-1907. doi:10.1213/ANE. 0000000000002742

Helander, E. M., Webb, M. P., Bias, M., Whang, E. E., Kaye, A. D., and Urman, R. D. (2017). A comparison of multimodal analgesic approaches in institutional enhanced recovery after surgery protocols for colorectal surgery: pharmacological agents. J. Laparoendosc. Adv. Surg. Tech. 27, 903-908. doi:10.1089/lap.2017.0338

Ho, Y. M., Smith, S. R., Pockney, P., Lim, P., and Attia, J. (2014). A meta-analysis on the effect of Sham feeding following colectomy. Dis. Colon Rectum 57, 115-126. doi:10.1097/DCR.0b013e3182a665be

Holte, K., Sharrock, N. E., and Kehlet, H. (2002). Pathophysiology and clinical implications of perioperative fluid excess. Br. J. Anaesth. 89, 622-632. doi:10. 1093/bja/aef220

Holubar, S. D., Hedrick, T., Gupta, R., Kellum, J., Hamilton, M., Gan, T. J., et al. (2017). American society for enhanced recovery (ASER) and perioperative quality initiative (POQI) joint consensus statement on prevention of postoperative infection within an enhanced recovery pathway for elective colorectal surgery. Perioperat. Med. 6, 1-18. doi:10.1186/s13741-017-0059-2

Hupa, K. J., Stein, K., Schneider, R., Lysson, M., Schneiker, B., Hornung, V., et al. (2019). AIM2 inflammasome-derived IL-1 $\beta$ induces postoperative ileus in mice. Sci. Rep. 9, 10602. doi:10.1038/s41598-019-46968-1

Hurley, R. W., Cohen, S. P., Williams, K. A., Rowlingson, A. J., and Wu, C. L. (2006). The analgesic effects of perioperative gabapentin on postoperative pain: a meta-analysis. Reg. Anesth. Pain Med. 31, 237-247. doi:10.1016/j.rapm.2006. 01.005

Isami, K., Haraguchi, K., So, K., Asakura, K., Shirakawa, H., Mori, Y., et al. (2013). Involvement of TRPM2 in peripheral nerve injury-induced infiltration of peripheral immune cells into the spinal cord in mouse neuropathic pain model. PLoS One 8, e66410. doi:10.1371/journal.pone.0066410

Kaji, N., Nakayama, S., Horiguchi, K., Iino, S., Ozaki, H., and Hori, M. (2018). Disruption of the pacemaker activity of interstitial cells of cajal via nitric oxide contributes to postoperative ileus. Neurogastroenterol. Motil. 30. doi:10.1111/ nmo.13334

Kalff, J. C., Schraut, W. H., Simmons, R. L., and Bauer, A. J. (1998). Surgical manipulation of the gut elicits an intestinal muscularis inflammatory response resulting in postsurgical ileus. Ann. Surg. 228, 652-663. doi:10.1097/00000658199811000-00004

Kane, T. D., Tubog, T. D., and Schmidt, J. R. (2020). The use of coffee to decrease the incidence of postoperative ileus: a systematic review and meta-analysis. J. Perianesth. Nurs. 35, 171-177. doi:10.1016/j.jopan.2019.07.004

Kehlet, H., and Joshi, G. P. (2017). Enhanced recovery after surgery. Anesth. Analg. 125, 2154-2155. doi:10.1213/ANE.0000000000002231

Kehlet, H. (1999). Surgical stress response: does endoscopic surgery confer an advantage? World J. Surg. 23, 801-807. doi:10.1007/s002689900583

Kehlet, H., and Wilmore, D. W. (2008). Evidence-based surgical care and the evolution of fast-track surgery. Ann. Surg. 248, 189-198. doi:10.1097/SLA. ob013e31817f2cla

Keller, D. S., Flores-Gonzalez, J. R., Ibarra, S., Mahmood, A., and Haas, E. M. (2016). Is there value in alvimopan in minimally invasive colorectal surgery? Am. J. Surg. 212, 851-856. doi:10.1016/j.amjsurg.2016.02.016

Khan, S. A., Khokhar, H. A., Nasr, A. R. H., Carton, E., and El-Masry, S. (2013). Effect of epidural analgesia on bowel function in laparoscopic colorectal 
surgery: a systematic review and meta-analysis. Surg. Endosc. 27, 2581-2591. doi:10.1007/s00464-013-2794-x

Kimura, H. (2013). "Hydrogen sulfide-mediated cellular signaling and cytoprotection," in Hydrogen sulfide and its therapeutic applications. New York, NY: Springer Vienna, 181-202.

Kimura, H., Imura, Y., Tomiyasu, H., Mihara, T., Kaji, N., Ohno, K., et al. (2019). Neural anti-inflammatory action mediated by two types of acetylcholine receptors in the small intestine. Sci. Rep. 9, 1-11. doi:10.1038/s41598-01941698-w

Kiran, R. P., Murray, A. C. A., Chiuzan, C., Estrada, D., and Forde, K. (2015). Combined preoperative mechanical bowel preparation with oral antibiotics significantly reduces surgical site infection, anastomotic leak, and ileus after colorectal surgery. Ann. Surg. 262, 416-425. doi:10.1097/SLA. 0000000000001416

Kirischuk, S. (2008). "Mechanosensitive channels in neuronal and astroglial cells in the nervous system," in Mechanosensitivity of the nervous system. Amsterdam, Netherlands: Springer, 3-22.

Klein, M., Krarup, P.-M., Burcharth, J., Ågren, M. S., Gögenur, I., Jorgensen, L. N., et al. (2011). Effect of diclofenac on cyclooxygenase-2 levels and early breaking strength of experimental colonic anastomoses and skin incisions. Eur. Surg. Res. 46, 26-31. doi:10.1159/000321706

Knotkova, H., and Pappagallo, M. (2007). Adjuvant analgesics. Anesthesiol. Clin. 25, 775-786. doi:10.1016/j.anclin.2007.07.006

Knowles, H., Li, Y., and Perraud, A. L. (2013). The TRPM2 ion channel, an oxidative stress and metabolic sensor regulating innate immunity and inflammation. Immunol. Res. 55, 241-248. doi:10.1007/s12026-012-8373-8

Koskenvuo, L., Lehtonen, T., Koskensalo, S., Rasilainen, S., Klintrup, K., Ehrlich, A., et al. (2019). Mechanical and oral antibiotic bowel preparation versus no bowel preparation for elective colectomy (MOBILE): a multicentre, randomised, parallel, single-blinded trial. Lancet 394, 840-848. doi:10.1016/ S0140-6736(19)31269-3

Langness, S., Kojima, M., Coimbra, R., Eliceiri, B. P., and Costantini, T. W. (2017). Enteric glia cells are critical to limiting the intestinal inflammatory response after injury. Am. J. Physiol.Gastrointest. Liver Physiol. 312, G274-G282. doi:10. 1152/ajpgi.00371.2016

Lei, Q.-C., Wang, X.-Y., Zheng, H.-Z., Xia, X.-F., Bi, J.-C., Gao, X.-J., et al. (2015). Laparoscopic vs. open colorectal resection within fast track programs: an update meta-analysis based on randomized controlled trials. J. Clin. Med. Res. 7, 594-601. doi:10.14740/jocmr2177w

Lewis, S. J., Andersen, H. K., and Thomas, S. (2009). Early enteral nutrition within $24 \mathrm{~h}$ of intestinal surgery versus later commencement of feeding: a systematic review and meta-analysis. J. Gastrointest. Surg. 13, 569-575. doi:10.1007/ s11605-008-0592-x

Lewis, S. J., Egger, M., Sylvester, P. A., and Thomas, S. (2001). Early enteral feeding versus "nil by mouth" after gastrointestinal surgery: systematic review and metaanalysis of controlled trials. Br. Med. J. 323, 773. doi:10.1136/bmj.323.7316.773

Liñán-Rico, A., Turco, F., Ochoa-Cortes, F., Harzman, A., Needleman, B. J., Arsenescu, R., et al. (2016). Molecular signaling and dysfunction of the human reactive enteric glial cell phenotype. Inflamm. Bowel Dis. 22, 1812-1834. doi:10.1097/MIB.0000000000000854

Li, S., Liu, Y., Peng, Q., Xie, L., Wang, J., and Qin, X. (2013). Chewing gum reduces postoperative ileus following abdominal surgery: a meta-analysis of 17 randomized controlled trials. J. Gastroenterol. Hepatol. 28, 1122-1132. doi:10.1111/jgh.12206

Linan-Rico, A., Ochoa-Cortes, F., Beyder, A., Soghomonyan, S., Zuleta-Alarcon, A., Coppola, V., et al. (2016). Mechanosensory signaling in enterochromaffin cells and 5-HT release: potential implications for gut inflammation. Front. Neurosci. 10, 1-19. doi:10.3389/fnins.2016.00564

Lobo, D. N., Bostock, K. A., Neal, K. R., Perkins, A. C., Rowlands, B. J., and Allison, S. P. (2002). Effect of salt and water balance on recovery of gastrointestinal function after elective colonic resection: a randomised controlled trial. Lancet 359, 1812-1818. doi:10.1016/S0140-6736(02)08711-1

Luckey, A., Livingston, E., and Tache, Y. (2003). Mechanisms and treatment of postoperative ileus. Arch. Surg. 138, 206-214. doi:10.1001/archsurg.138.2.206

Luyer, M. D., Greve, J. W. M., Hadfoune, M., Jacobs, J. A., Dejong, C. H., and Buurman, W. A. (2005). Nutritional stimulation of cholecystokinin receptors inhibits inflammation via the vagus nerve. J. Exp. Med. 202, 1023-1029. doi:10. 1084/jem.20042397
Müller, S. A., Rahbari, N. N., Schneider, F., Warschkow, R., Simon, T., von Frankenberg, M., et al. (2012). Randomized clinical trial on the effect of coffee on postoperative ileus following elective colectomy. Br. J. Surg. 99, 1530-1538. doi:10.1002/bjs.8885

Magierowski, M., Magierowska, K., Surmiak, M., Hubalewska-Mazgaj, M., Kwiecien, S., Wallace, J., et al. (2017). The effect of hydrogen sulfidereleasing naproxen (ATB-346) vs. naproxen on formation of stress-induced gastric lesions, the regulation of systemic inflammation, hypoxia and alterations in gastric microcirculation. J. Physiol. Pharmacol. 68, 749-756.

Mamidanna, R., Burns, E. M., Bottle, A., Aylin, P., Stonell, C., Hanna, G. B., et al. (2012). Reduced risk of medical morbidity and mortality in patients selected for laparoscopic colorectal resection in England: a population-based study. Arch. Surg. 147, 219-227. doi:10.1001/archsurg.2011.311

Matsumoto, K., Kawanaka, H., Hori, M., Kusamori, K., Utsumi, D., Tsukahara, T., et al. (2018). Role of transient receptor potential melastatin 2 in surgical inflammation and dysmotility in a mouse model of postoperative ileus. Am. J. Physiol. Gastrointest. Liver Physiol. 315, G104-G116. doi:10.1152/ajpgi.00305.2017

Matsunami, M., Kirishi, S., Okui, T., and Kawabata, A. (2012). Hydrogen sulfideinduced colonic mucosal cytoprotection involves T-type calcium channeldependent neuronal excitation in rats. J. Physiol. Pharmacol. 63, 61-68.

Matteoli, G., Gomez-Pinilla, P. J., Nemethova, A., Giovangiulio, M. D., Cailotto, C., Van Bree, S. H., et al. (2014). A distinct vagal anti-inflammatory pathway modulates intestinal muscularis resident macrophages independent of the spleen. Gut 63, 938-948. doi:10.1136/gutjnl-2013-304676

Mazzotta, E., Villalobos-Hernandez, E. C., Harzman, A., and Christofi, F. L. (2020). Impact of minimal invasive robotic surgery on recovery from postoperative ileus and postoperative gastrointestinal tract dysfunction. Am. J. Biomed. Sci. Res. 8, 535-538. doi:10.34297/ajbsr.2020.08.001335

Mazzotta, E., Villalobos-Hernandez, E. C., Schneider, R., Leven, P., McClain, J. L., Soghomonyan, S., et al. (2019). Su1309-impact of gut surgical manipulation on enteric glia, Ca2+ waves, ADP Signaling, neural-glial communication, ET-1 siganling and molecular signaling in a mouse model of postoperative ileus. Gastroenterology 156, S537. doi:10.1016/s0016-5085(19)38234-4

McLean, P. G., Picard, C., Garcia-Villar, R., Moré, J., Fioramonti, J., and Buéno, L. (1997). Effects of nematode infection on sensitivity to intestinal distension: role of tachykinin $\mathrm{NK}_{2}$ receptors. Eur. J. Pharmacol. 337, 279-282. doi:10.1016/ S0014-2999(97)01275-2

Meng, Z. Q., Garcia, M. K., Chiang, J. S., Peng, H. T., Shi, Y. Q., Fu, J., et al. (2010). Electro-acupuncture to prevent prolonged postoperative ileus: a randomized clinical trial. World J. Gastroenterol. 16, 104-111. doi:10.3748/wjg.v16.i1.104

Mihara, T., Otsubo, W., Horiguchi, K., Mikawa, S., Kaji, N., Iino, S., et al. (2017). The anti-inflammatory pathway regulated via nicotinic acetylcholine receptors in rat intestinal mesothelial cells. J. Vet. Med. Sci. 79, 1795-1802. doi:10.1292/ jvms.17-0304

Miller, T. E., Thacker, J. K., White, W. D., Mantyh, C., Migaly, J., Jin, J., et al. (2014). Reduced length of hospital stay in colorectal surgery after implementation of an enhanced recovery protocol. Anesth. Analg. 118, 1052-1061. doi:10.1213/ANE. 0000000000000206

Milne, T. G. E., Jaung, R., O'Grady, G., and Bissett, I. P. (2018). Nonsteroidal antiinflammatory drugs reduce the time to recovery of gut function after elective colorectal surgery: a systematic review and meta-analysis. Colorectal Dis. 20, O190-O198. doi:10.1111/codi.14268

Mishriky, B. M., Waldron, N. H., and Habib, A. S. (2015). Impact of pregabalin on acute and persistent postoperative pain: a systematic review and meta-analysis. Br. J. Anaesth. 114, 10-31. doi:10.1093/bja/aeu293

Moojen, T. M., Van Gulik, T. M., Hoek, F. J., Gouma, D. J., Tytgat, G. N. J., and Boeckxstaens, G. E. E. (1999). Possible role of nitric oxide in postoperative ileus: a comparative study. Neurogastroenterol. Motil. 11, 403-408. doi:10.1046/j. 1365-2982.1999.00158.x

Moore, B. A., Otterbein, L. E., Türler, A., Choi, A. M. K., and Bauer, A. J. (2003), Inhaled carbon monoxide suppresses the development of postoperative ileus in the murine small intestine. Gastroenterology 124, 377-391. doi:10.1053/gast. 2003.50060

Moore-Olufemi, S. D., Xue, H., Attuwaybi, B. O., Fischer, U., Harari, Y., Oliver, D. H., et al. (2005). Resuscitation-induced gut edema and intestinal dysfunction. J. Trauma Inj. Infect. Crit. Care 58, 264-270. doi:10.1097/01.TA.0000133571.64393.D2

Morris, M. S., Graham, L. A., Chu, D. I., Cannon, J. A., and Hawn, M. T. (2015). Oral antibiotic bowel preparation significantly reduces surgical site infection 
rates and readmission rates in elective colorectal surgery. Ann. Surg. 261, 1034-1040. doi:10.1097/SLA.0000000000001125

Myrhöj, T., Olsen, O., and Wengel, B. (1988). Neostigmine in postoperative intestinal paralysis-a double-blind, clinical, controlled trial. Heidelberg, Germany: Springer-Verlag, 378-379.

Nahrendorf, M., Pittet, M. J., and Swirski, F. K. (2010). Monocytes: protagonists of infarct inflammation and repair after myocardial infarction. Circulation 121, 2437-2445. doi:10.1161/CIRCULATIONAHA.109.916346

Nakao, A., Schmidt, J., Harada, T., Tsung, A., Stoffels, B., Cruz, R. J., et al. (2006). A single intraperitoneal dose of carbon monoxide-saturated Ringer's lactate solution ameliorates postoperative ileus in mice. J. Pharmacol. Exp. Therapeut. 319, 1265-1275. doi:10.1124/jpet.106.108654

Nelson, G., Kiyang, L. N., Crumley, E. T., Chuck, A., Nguyen, T., Faris, P., et al. (2016). Implementation of enhanced recovery after surgery (ERAS) across a provincial healthcare system: the ERAS Alberta colorectal surgery experience. World J. Surg. 40, 1092-1103. doi:10.1007/s00268-016-3472-7

Ng, S. S. M., Leung, W. W., Mak, T. W. C., Hon, S. S. F., Li, J. C. M., Wong, C. Y. N., et al. (2013). Electroacupuncture reduces duration of postoperative ileus after laparoscopic surgery for colorectal cancer. Gastroenterology 144, 307-313. doi:10.1053/j.gastro.2012.10.050

Nimmo, S. M., and Harrington, L. S. (2014). What is the role of epidural analgesia in abdominal surgery? Cont. Educ. Anaesth. Crit. Care Pain 14, 224-229. doi:10. 1093/bjaceaccp/mkt062

Nisanevich, V., Felsenstein, I., Almogy, G., Weissman, C., Einav, S., and Matot, I. (2005). Effect of intraoperative fluid management on outcome after intraabdominal surgery. Anesthesiology 103, 25-32. doi:10.1097/00000542200507000-00008

Novitsky, Y. W., Litwin, D. E. M., and Callery, M. P. (2004). The net immunologic advantage of laparoscopic surgery. Surg. Endosc. Other Interv. Tech. 18, 1411-1419. doi:10.1007/s00464-003-8275-x

Ochoa-Cortes, F., Turco, F., Linan-Rico, A., Soghomonyan, S., Whitaker, E., Wehner, S., et al. (2016). Enteric glial cells: a new frontier in neurogastroenterology and clinical target for inflammatory bowel diseases. Inflamm. Bowel Dis. 22, 433-449. doi:10.1097/MIB.0000000000000667

Pecorelli, N., Hershorn, O., Baldini, G., Fiore, J. F., Jr, Stein, B. L., Sender Liberman, A., et al. (2017). Impact of adherence to care pathway interventions on recovery following bowel resection within an established enhanced recovery program and other interventional techniques. Surg. Endosc. 31, 1760-1771. doi:10.1007/ s00464-016-5169-2

Peters, E. G., De Jonge, W. J., Smeets, B. J. J., and Luyer, M. D. P. (2015). The contribution of mast cells to postoperative ileus in experimental and clinical studies. Neurogastroenterol. Motil. 27, 743-749. doi:10.1111/nmo.12579

Peters, E. G., Pattamatta, M., Smeets, B. J. J., Brinkman, D. J., Evers, S. M. A. A., Jonge, W. J., et al. (2020). The clinical and economical impact of postoperative ileus in patients undergoing colorectal surgery. Neurogastroenterol. Motil. 00, e13862. doi:10.1111/nmo.13862

Prather, C. M., Camilleri, M., Zinsmeister, A. R., McKinzie, S., and Thomforde, G. (2000). Tegaserod accelerates orocecal transit in patients with constipationpredominant irritable bowel syndrome. Gastroenterology 118, 463-468. doi:10. 1016/S0016-5085(00)70251-4

Rao, S. S. C., Welcher, K., Zimmerman, B., and Stumbo, P. (1998). Is coffee a colonic stimulant? Eur. J. Gastroenterol. Hepatol. 10, 113-118. doi:10.1097/ 00042737-199802000-00003

Rohloff, M., Cicic, A., Christensen, C., Maatman, T. K., Lindberg, J., and Maatman, T. J. (2019). Reduction in postoperative ileus rates utilizing lower pressure pneumoperitoneum in robotic-assisted radical prostatectomy. J. Robot. Surg. 13, 671-674. doi:10.1007/s11701-018-00915-w

Rundshagen, I. (2014). Postoperative cognitive dysfunction. Dtsch. Arztebl. Int. 111, 119-125. doi:10.3238/arztebl.2014.0119.

Rushfeldt, C. F., Sveinbjørnsson, B., Søreide, K., and Vonen, B. (2011). Risk of anastomotic leakage with use of NSAIDs after gastrointestinal surgery. Int. J. Colorectal Dis. 26, 1501-1509. doi:10.1007/s00384-011-1285-6

Sandrasegaran, K., and Maglinte, D. D. T. (2005). Imaging of small bowel-related complications following major abdominal surgery. Eur. J. Radiol. 53, 374-386. doi:10.1016/j.ejrad.2004.12.017

Schietroma, M., Carlei, F., Cecilia, E. M., Piccione, F., Sista, F., De Vita, F., et al. (2013). A prospective randomized study of systemic inflammation and immune response after laparoscopic nissen fundoplication performed with standard and low-pressure pneumoperitoneum. Surg. Laparosc. Endosc. Percutaneous Tech. 23, 189-196. doi:10.1097/SLE.0b013e3182827e51

Schietroma, M., Pessia, B., Stifini, D., Lancione, L., Carlei, F., Cecilia, E. M., et al. (2016). Effects of low and standard intra-abdominal pressure on systemic inflammation and immune response in laparoscopic adrenalectomy: a prospective randomised study. J. Minimal Access Surg. 12, 109-117. doi:10. 4103/0972-9941.178513

Schnüriger, B., Inaba, K., Wu, T., Eberle, B. M., Belzberg, H., and Demetriades, D. (2011). Crystalloids after primary colon resection and anastomosis at initial trauma laparotomy: excessive volumes are associated with anastomotic leakage. J. Trauma Inj. Infect. Crit. Care 70, 603-610. doi:10.1097/TA.0b013e3182092abb

Schwenk, W., Böhm, B., Haase, O., Junghans, T., and Müller, J. M. (1998). Laparoscopic vs. conventional colorectal resection: a prospective randomised study of postoperative ileus and early postoperative feeding. Langenbeck's Arch. Surg. 383, 49-55. doi:10.1007/s004230050091

Schwenk, W., Haase, O., Neudecker, J. J., and Müller, J. M. (2005). Short term benefits for laparoscopic colorectal resection. Cochrane Database Syst. Rev. 20 (3), CD003145. doi:10.1002/14651858.cd003145.pub2

Serhan, C. N., and Savill, J. (2005). Resolution of inflammation: the beginning programs the end. Nat. Immunol. 6, 1191-1197. doi:10.1038/ni1276

Shah, S. K., Uray, K. S., Stewart, R. H., Laine, G. A., and Cox, C. S. (2011). Resuscitation-induced intestinal edema and related dysfunction: state of the science. J. Surg. Res. 166, 120-130. doi:10.1016/j.jss.2009.09.010

Shaw, M., Pediconi, C., McVey, D., Mondou, E., Quinn, J., Chamblin, B., et al. (2013). safety and efficacy of ulimorelin administered postoperatively to accelerate recovery of gastrointestinal motility following partial bowel resection. Dis. Colon Rectum 56, 888-897. doi:10.1097/DCR. 0b013e31829196d0

Shechter, R., London, A., Varol, C., Raposo, C., Cusimano, M., Yovel, G., et al. (2009). Infiltrating blood-derived macrophages are vital cells playing an antiinflammatory role in recovery from spinal cord injury in mice. PLoS Med. 6 (7), e1000113. doi:10.1371/journal.pmed.1000113

Short, V., Herbert, G., Perry, R., Atkinson, C., Ness, A. R., Penfold, C., et al. (2015). Chewing gum for postoperative recovery of gastrointestinal function. Cochrane Database Syst. Rev. 20 (2), CD006506. doi:10.1002/14651858.CD006506.pub3

Slim, K., and Joris, J. (2017). The egg-and-chicken situation in postoperative enhanced recovery programmes. Br. J. Anaesth. 118, 5-6. doi:10.1093/bja/aew408

Smith, A. J., Nissan, A., Lanouette, N. M., Shi, W., Guillem, J. G., Wong, W. D., et al. (2000). Prokinetic effect of erythromycin after colorectal surgery: randomized, placebo-controlled, double-blind study. Dis. Colon Rectum 43, 333-337. doi:10. 1007/BF02258298

Sobczak, M., Sałaga, M., Storr, M. A., and Fichna, J. (2014). Physiology, signaling, and pharmacology of opioid receptors and their ligands in the gastrointestinal tract: current concepts and future perspectives. J. Gastroenterol. 49, 24-45. doi:10.1007/s00535-013-0753-x

Srinivasa, S., Taylor, M. H. G., Singh, P. P., Yu, T.-C., Soop, M., and Hill, A. G. (2013). Randomized clinical trial of goal-directed fluid therapy within an enhanced recovery protocol for elective colectomy. Artic. Br. J. Surg. 100, 66-74. doi:10.1002/bjs.8940

Stakenborg, N., Labeeuw, E., Gomez-Pinilla, P. J., De Schepper, S., Aerts, R., Goverse, G., et al. (2019). Preoperative administration of the 5-HT4 receptor agonist prucalopride reduces intestinal inflammation and shortens postoperative ileus via cholinergic enteric neurons. Gut 68, 1406-1416. doi:10.1136/gutjnl-2018-317263

Stakenborg, N., Wolthuis, A. M., Gomez-Pinilla, P. J., Farro, G., Di Giovangiulio, M., Bosmans, G., et al. (2017). Abdominal vagus nerve stimulation as a new therapeutic approach to prevent postoperative ileus. Neurogastroenterol. Motil. 29. doi:10.1111/nmo.13075

Stein, K., Hieggelke, L., Schneiker, B., Lysson, M., Stoffels, B., Nuding, S., et al. (2018). Intestinal manipulation affects mucosal antimicrobial defense in a mouse model of postoperative ileus. PLoS One 13, e0195516. doi:10.1371/ journal.pone.0195516

Steinmetz, J., Christensen, K. B., Lund, T., Lohse, N., and Rasmussen, L. S. (2009). Long-term consequences of postoperative cognitive dysfunction. Anesthesiology 110, 548-555. doi:10.1097/ALN.0b013e318195b569

Stoffels, B., Hupa, K. J., Snoek, S. A., Van Bree, S., Stein, K., Schwandt, T., et al. (2014). Postoperative ileus involves interleukin-1 receptor signaling in enteric glia. Gastroenterology 146, 176-187. doi:10.1053/j.gastro.2013.09.030 
Stoffels, B., Schmidt, J., Nakao, A., Nazir, A., Chanthaphavong, R. S., and Bauer, A. J. (2009). Role of interleukin 10 in murine postoperative ileus. Gut 58, 648-660. doi:10.1136/gut.2008.153288

Straube, S., Derry, S., McQuay, H. J., and Moore, R. A. (2005). Effect of preoperative Cox-II-selective NSAIDs (coxibs) on postoperative outcomes: a systematic review of randomized studies. Acta Anaesthesiol. Scand. 49, 601-613. doi:10. 1111/j.1399-6576.2005.00666.x

Strom, B. L., Berlin, J. A., Kinman, J. L., Spitz, P. W., Hennessy, S., Feldman, H., et al. (1996). Parenteral ketorolac and risk of gastrointestinal and operative site bleeding. J. Am. Med. Assoc. 275, 382. doi:10.1001/jama.1996.03530290046036

Suchyna, T. M. (2017). Piezo channels and GsMTx4: two milestones in our understanding of excitatory mechanosensitive channels and their role in pathology. Prog. Biophys. Mol. Biol. 130, 244-253. doi:10.1016/j.pbiomolbio. 2017.07.011

Sun, D.-L., Qi, Y.-X., Yang, T., Lin, Y.-Y., Li, S.-M., Li, Y.-J., et al. (2020). Early oral nutrition improves postoperative ileus through the TRPA1/CCK1-R-mediated mast cell-nerve axis. Ann. Transl. Med. 8, 179. doi:10.21037/atm.2020.01.95

Sun, Y., Li, T., Wang, N., Yun, Y., and Gan, T. J. (2012). Perioperative systemic lidocaine for postoperative analgesia and recovery after abdominal surgery. Dis. Colon Rectum 55, 1183-1194. doi:10.1097/DCR.0b013e318259bcd8

Takahashi, T. (2006). Acupuncture for functional gastrointestinal disorders. J. Gastroenterol. 41, 408-417. doi:10.1007/s00535-006-1773-6

The, F. O., Bennink, R. J., Ankum, W. M., Buist, M. R., Busch, O. R. C., Gouma, D. J., et al. (2008). Intestinal handling-induced mast cell activation and inflammation in human postoperative ileus. Gut 57, 33-40. doi:10.1136/gut.2007.120238

Tollesson, P. O., Cassuto, J., Faxen, A., Rimback, G., Mattsson, E., and Rosen, S. (1991). Lack of effect of metoclopramide on colonic motility after cholecystectomy. Acta Chir. Eur. J. Surg. 157, 355-358.

Torgeson, M., Kileny, J., Pfeifer, C., Narkiewicz, L., and Obi, S. (2018). Conventional epidural vs transversus abdominis plane block with liposomal bupivacaine: a randomized trial in colorectal surgery. J. Am. Coll. Surg. 227, 78-83. doi:10.1016/j.jamcollsurg.2018.04.021

Tsuchiya, K., Kubota, K., Ohbuchi, K., Kaneko, A., Ohno, N., Mase, A., et al. (2016). Transient receptor potential ankyrin 1 agonists improve intestinal transit in a murine model of postoperative ileus. Neurogastroenterol. Motil. 28, 1792-1805. doi:10.1111/nmo.12877

Uray, K. S., Laine, G. A., Xue, H., Allen, S. J., and Cox, C. S. (2006). Intestinal edema decreases intestinal contractile activity via decreased myosin light chain phosphorylation. Crit. Care Med. 34, 2630-2637. doi:10.1097/01.CCM. 0000239195.06781.8C

Valès, S., Touvron, M., and Van Landeghem, L. (2018). Enteric glia: diversity or plasticity? Brain Res. 1693, 140-145. doi:10.1016/j.brainres.2018.02.001

Van Bree, S., Vlug, M., Bemelman, W., Hollmann, M., Ubbink, D., Zwinderman, A. H., et al. (2011). Faster recovery of gastrointestinal transit after laparoscopy and fast-track care in patients undergoing colonic surgery. Gastroenterology 141, 872-880. doi:10.1053/j.gastro.2011.05.034

Van Dingenen, J., Pieters, L., Vral, A., and Lefebvre, R. A. (2019). The H2Sreleasing naproxen derivative ATB-346 and the slow-release H2S donor GYY4137 reduce intestinal inflammation and restore transit in postoperative ileus. Front. Pharmacol. 10, 116. doi:10.3389/fphar.2019.00116

Varadhan, K. K., Neal, K. R., Dejong, C. H. C., Fearon, K. C. H., Ljungqvist, O., and Lobo, D. N. (2010). The enhanced recovery after surgery (ERAS) pathway for patients undergoing major elective open colorectal surgery: a meta-analysis of randomized controlled trials. Clin. Nutr. 29, 434-440. doi:10.1016/j.clnu.2010.01.004

Vasdev, N., Nidhin, R., Linda, F., Gowrie, M. S., Prasad, V., Thakur, S., et al. (2018). "Cytokine guided robotic prostatectomy," in European urology supplements. Amsterdam, Netherlands: Elsevier BV, e1860. |

Vather, R., Josephson, R., Jaung, R., Robertson, J., and Bissett, I. (2015). Development of a risk stratification system for the occurrence of prolonged postoperative ileus after colorectal surgery: a prospective risk factor analysis. Surgery 157, 764-773. doi:10.1016/j.surg.2014.12.005

Vather, R., Trivedi, S., and Bissett, I. (2013). Defining postoperative ileus: results of a systematic review and global survey. J. Gastrointest. Surg. 17, 962-972. doi:10. 1007/s11605-013-2148-y

Vaughan-Shaw, P. G., Fecher, I. C., Harris, S., and Knight, J. S. (2012). A metaanalysis of the effectiveness of the opioid receptor antagonist alvimopan in reducing hospital length of stay and time to GI recovery in patients enrolled in a standardized accelerated recovery program after abdominal surgery. Dis. Colon Rectum 55, 611-620. doi:10.1097/DCR.0b013e318249fc78

Verma, R., and Nelson, R. (2007). Prophylactic nasogastric decompression after abdominal surgery. Cochrane Database Syst. Rev. 2007 (3), CD004929. doi:10. 1002/14651858.CD004929.pub3

Viscusi, E. R., Gan, T. J., Leslie, J. B., Foss, J. F., Talon, M. D., Du, W., et al. (2009). Peripherally acting mu-Opioid receptor antagonists and postoperative ileus: mechanisms of action and clinical applicability. Anesth. Analg. 108, 1811-1822. doi:10.1213/ane.0b013e31819e0d3a

Wallace, J. L. (2007). Hydrogen sulfide-releasing anti-inflammatory drugs. Trends Pharmacol. Sci. 28, 501-505. doi:10.1016/j.tips.2007.09.003

Wallace, J. L., Vaughan, D., Dicay, M., Macnaughton, W. K., and De Nucci, G. (2018). Hydrogen sulfide-releasing therapeutics: translation to the clinic. Antioxidants Redox Signal. 28, 1533-1540. doi:10.1089/ars.2017.7068

Wang, F., Knutson, K., Alcaino, C., Linden, D. R., Gibbons, S. J., Kashyap, P., et al. (2017). Mechanosensitive ion channel Piezo2 is important for enterochromaffin cell response to mechanical forces. J. Physiol. 595, 79-91. doi:10.1113/JP272718

Wang, H., Wang, Y., Xing, H., Zhou, Y., Zhao, J., Jiang, J., et al. (2018). Laparoscopic surgery within an enhanced recovery after surgery (ERAS) protocol reduced postoperative ileus by increasing postoperative treg levels in patients with right-side colon carcinoma. Med. Sci. Monit. 24, 7231-7237. doi:10.12659/MSM.910817

Wehner, S., and Engel, D. R. (2017). Resident macrophages in the healthy and inflamed intestinal muscularis externa. Pflugers Arch. Eur. J. Physiol. 469, 541-552. doi:10.1007/s00424-017-1948-4

Wick, E. C., Grant, M. C., and Wu, C. L. (2017). Postoperative multimodal analgesia pain management with nonopioid analgesics and techniques a review. JAMA Surg. 152, 691-697. doi:10.1001/jamasurg.2017.0898

Wolthuis, A. M., Bislenghi, G., Fieuws, S., de Buck van Overstraeten, A., Boeckxstaens, G., and D'Hoore, A. (2016). Incidence of prolonged postoperative ileus after colorectal surgery: a systematic review and metaanalysis. Colorectal Dis. 18, O1-O9. doi:10.1111/codi.13210

Wouters, M. M., Vicario, M., and Santos, J. (2016). The role of mast cells in functional GI disorders. Gut 65, 155-168. doi:10.1136/gutjnl-2015-309151

Xiong, Y. D., Rong, L. X., and Pan, C. (2017). Regulation of postoperative ileus by lentivirus-mediated HuR RNA interference via the p38/MK2 signaling pathway. J. Gastrointest. Surg. 21, 389-397. doi:10.1007/s11605-016-3303-z

Yuan, P. Q., and Taché, Y. (2017). Abdominal surgery induced gastric ileus and activation of M1-like macrophages in the gastric myenteric plexus: prevention by central vagal activation in rats. Am. J. Physiol. Gastrointest. Liver Physiol. 313, G320-G329. doi:10.1152/ajpgi.00121.2017

Zhang, Z., Wang, C., Li, Q., Zhang, M., Zhao, H., Dong, L., et al. (2014). Electroacupuncture at ST36 accelerates the recovery of gastrointestinal motility after colorectal surgery: a randomised controlled trial. Acupunct. Med. 32, 223-226. doi:10.1136/acupmed-2013-010490

Zhuang, C.-L., Ye, X.-Z., Zhang, C.-J., Dong, Q.-T., Chen, B.-C., and Yu, Z. (2013). Early versus traditional postoperative oral feeding in patients undergoing elective colorectal surgery: a meta-analysis of randomized clinical trials. Dig. Surg. 30, 225-232. doi:10.1159/000353136

Zigmond, E., Samia-Grinberg, S., Pasmanik-Chor, M., Brazowski, E., Shibolet, O., Halpern, Z., et al. (2014). Infiltrating monocyte-derived macrophages and resident kupffer cells display different ontogeny and functions in acute liver injury. J. Immunol. 193, 344-353. doi:10.4049/jimmunol.1400574

Conflict of Interest: FC, EM, and JFD are Co-Investigators on a multi-center clinical trial on postoperative ileus with TAKEDA.

The remaining authors declare that the research was conducted in the absence of any commercial or financial relationships that could be construed as a potential conflict of interest.

Copyright $(2020$ Mazzotta, Villalobos-Hernandez, FIORDA-DIAZ, Harzman and Christofi. This is an open-access article distributed under the terms of the Creative Commons Attribution License (CC BY). The use, distribution or reproduction in other forums is permitted, provided the original author(s) and the copyright owner(s) are credited and that the original publication in this journal is cited, in accordance with accepted academic practice. No use, distribution or reproduction is permitted which does not comply with these terms. 